\title{
Reactive plasticity for clays: application to a natural analog of long- term geomechanical effects of nuclear waste disposal
}

\author{
Tomasz Hueckel $^{\mathrm{a}, *}$, Rita Pellegrini ${ }^{\mathrm{b}}$ \\ ${ }^{a}$ Department of Civil and Environmental Engineering, Duke University, Pratt School of Engineering, Durham, NC 27708, USA \\ ${ }^{\mathrm{b}}$ ENEL.HYDRO-BU ISMES, Bergamo, Italy
}

Received 9 November 2000; accepted 17 October 2001

\begin{abstract}
Long-term changes in mechanical properties of clays induced by heating are investigated based on findings at Orciatico site of natural analog of nuclear waste disposal. To quantify the extent of such changes, a chemo-thermo-plastic model for illitization and re-smectitization of clays [Int. J. Plast. (2000)] is used. The model is an extension of Cam-clay model. Identification of parameters is presented for the material from one peripheral borehole where temperatures developed in clay near the contact were in the analogy range. Short-term heating experiments on previously thermally unaffected specimens were used to identify thermal softening characteristics. Apparent maximum past precompression stress was determined throughout the borehole. Hypothetical history of the clay in the borehole including pre-loading, heating, cooling and mineralogical reaction was reconstructed, and the apparent maximum past precompression stress data were used to identify the characteristics of chemical softening function describing the long-term clay transformations. (C) 2002 Elsevier Science B.V. All rights reserved.
\end{abstract}

\section{Introduction}

This paper discusses an application of a previously developed coupled chemo-mechanical model of reactive plasticity for dehydration and rehydration of clays (Hueckel, 2002) to the analysis of long-term impact of heat from nuclear waste on mechanical properties of clays. The model is used to study geomechanical aspects of a natural analog of nuclear waste disposal in clays. Natural analogs are one of the primary tools to

\footnotetext{
${ }^{*}$ Corresponding author.

E-mail addresses: hueckel@duke.edu (T. Hueckel), pellegrini.rita@enel.it (R. Pellegrini).
}

calibrate models for long-term phenomena used for performance assessment of waste disposal. Most of the recent experience with thermal effects in soil mechanics has been gained in the course of the development of technologies of deep continental disposal of High Level Radioactive Waste (HLW) in clay formations (see, e.g. Gera et al., 1996), and earlier work on seabed disposal (see, e.g. Campanella and Mitchell, 1968). For the continental disposal of interest here, the central concept is that of a multiple barrier. Such a barrier consists of waste package, including metal and concrete containers, an engineered barrier of backfill and buffer, and the host geologic formation. The containers are designed to fail within about 300 years, what implies a release of the nuclear contaminant into 
groundwater. Thus, at this point, the clay buffer and the indigenous rock/clay formation itself become the ultimate containment barrier. The HLW heat output decreases exponentially with time, depending also on the delay time with respect to the discharge from reactor. The delay time is intended to decrease the temperature at the contact of the waste container with soil to about 100 to $150{ }^{\circ} \mathrm{C}$. This latter temperature value is one of the main factors in the design of repositories, as seen below.

There are two principal ways in which heat may affect the mechanical and hydraulic performance of a repository. One is short-term, and regards heat-induced stress and pore pressure changes that subside after the decay heat output decreases to the background levels. That includes possible advection of radionuclides with the pore pressure gradient induced water flow away from the repository and toward the biosphere. Temperature increases the pore water pressure due to the difference in thermal expansion of water and mineral matrix. The other mechanism is through irreversible changes in mineralogical soil makeup affecting strength, strain and permeability with a long-term impact.

Thermal increase of pore water pressure through its gradient may substantially increase the natural water flow, enhancing a potential contaminant transport if an early breakdown of the inner engineered barrier occurs. On the other hand, pore pressure evolution itself may lead to an excessive decrease in the effective stress, decreasing in turn the safety factor against local mechanical failure of clay mass. This is most likely to occur during the cooling phase. The mechanical failure may affect also the hydraulic conductivity. The pore pressure development may be controlled by the spacing of tunnels and/or boreholes containing waste, which becomes a principal design parameter.

Most of the experience with the thermal effects of nuclear waste on clays is based on short-term laboratory or in situ experiments (see, e.g. Hueckel and Baldi, 1990; Graham et al., 1996; Picard et al., 1993). As for the long-term response of barriers, which is the core of the Performance Assessment exercise, very little is known indeed. Heating related, mineralogical or physico-chemical changes of the materials involved are feared to seriously affect their hydraulic isolation and mechanical strength capabilities. This is especially important with materials like clays because of the physico-chemical nature of the mechanisms responsible for the long-term stability of their most important properties: low intrinsic permeability and high plasticity. The major shortcoming regarding the long-term stability of permeability and plasticity is the current lack of experimental data of a significantly long duration.

One avenue in overcoming this major deficiency in our understanding and predicting long-term thermal effects of nuclear waste on clays is to study natural analogs of such effects on clays in the field conditions. One type of such natural analog has been identified in clay formations near contact with volcanic intrusions. A number of studies of natural analogs, consisting in intrusion of hot magmatic mass into clays have been conducted concentrating on mineralogical changes (see, e.g. Pytte and Reynolds, 1989; Ferry et al., 1987; Kamei et al., 1990; Pusch and Madsen, 1995). They suggest massive illitization of smectitic parent clay in the temperature of analogy. As will be seen below that is not always the dominant scenario.

In comparison to laboratory testing, the observation and analysis of natural analogs offer a number of advantages. These are: (i) the duration of the exposure to heat, comparable to that of nuclear waste decay heat (hundreds of years), leading also to comparable rates of other processes; (ii) geometrical size of the volume exposed, allowing for development of gradient dependent phenomena such as thermal conduction and water flow; and (iii) representativeness of the size of the specimen, including natural inhomogeneities of mineralogical, physical and mechanical kind, elements of secondary structure such as possible fractures, faults, and shear bands, filled or not with fresh sediment. There are also shortcomings of natural analogs as simulators of HLW disposal, such as: (i) the actual temperature of intrusion, which usually is much higher than that of nuclear waste, requiring a careful identification of the zone of the actual thermal analogy; (ii) effects of mechanical penetration of volcanic rock into clay mass with the corresponding strain; (iii) observability only of the terminal state of the entire thermal cycle; and (iv) superposition of possible effects of post-analog history, such as unloading due to weathering, with the consequent exhumation of the site, natural erosion process, etc.

The principal goal in investigating geomechanics of a natural analog is to establish a relationship between 
alterations of hydro-mechanical properties of clay, such as overconsolidation, strength, permeability or fracturation, and the spatial variability of the mineralogical alterations of clay, as a function of "temperature dis- tance" from the hypothetical heat source. In this study, such relationship will be cast within the framework of a thermo-chemo-mechanical model including reactive plasticity developed earlier (Hueckel, 2002).

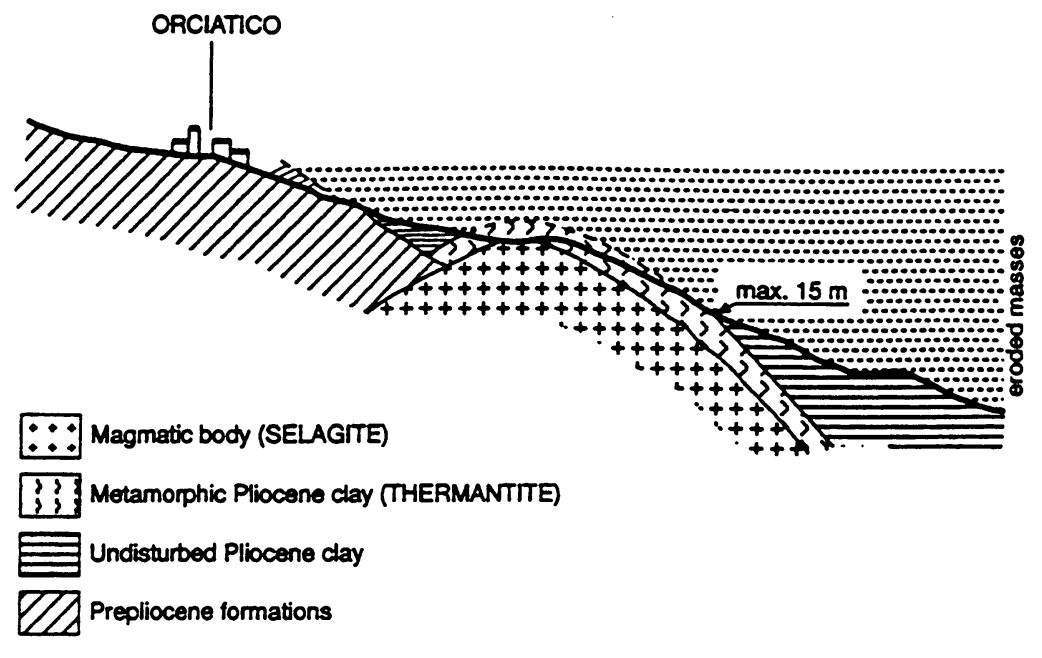

(a)
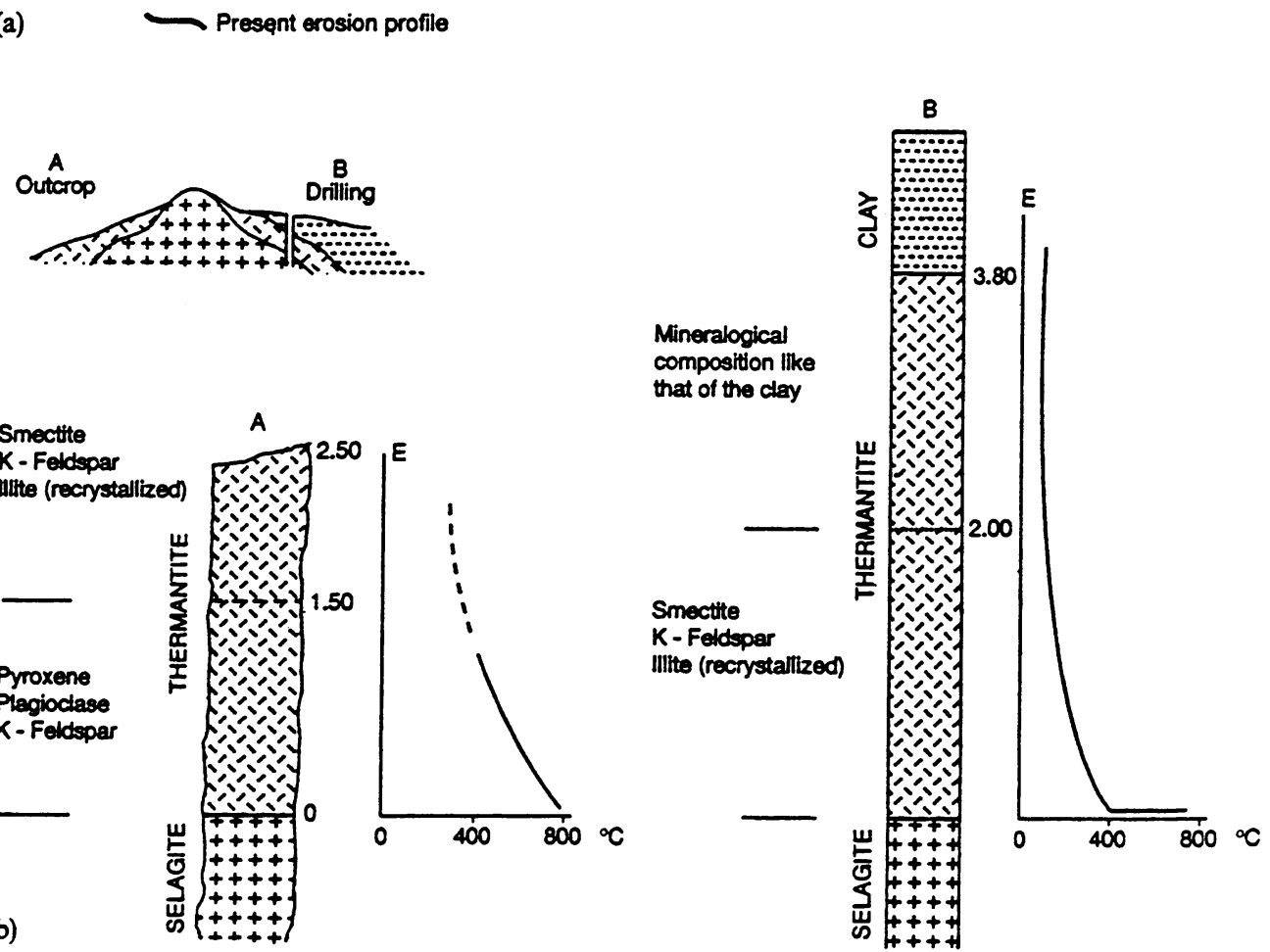

(b)

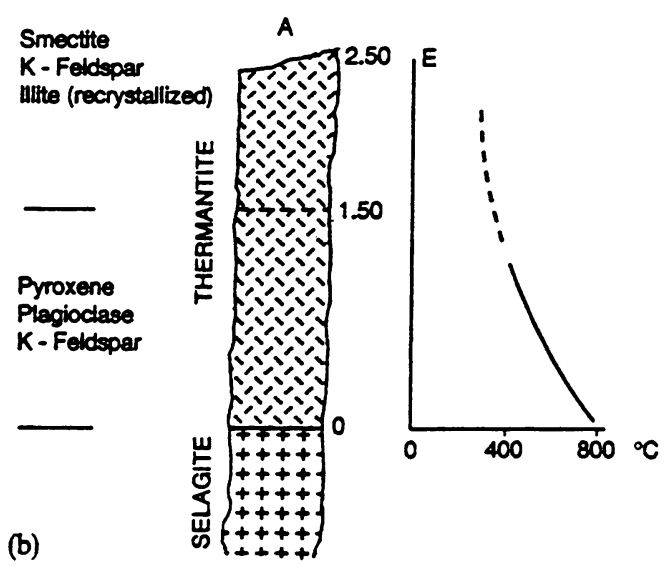

Fig. 1. General layout of the natural analog site at Orciatico, Italy (early assessment by ENEA): (a) geological cross-section; (b) geological profiles at locations A and B. Also shown are distances (in meters) from the presumed contact with magma (selagite) (after Benvegnu et al., 1988). 
The key issue is thus in a proper evaluation of the type and extent of chemical and mineralogical changes and their significance to the mechanical changes in clay properties. The role of chemical changes in the performance of clay barriers against nuclear waste migration has traditionally been limited to the evaluation of transport rate of the radioactive species involved. Mechanics and hydraulics of clay barriers were largely believed to be independent of the chemistry of pore liquid or the minerals. The motivation for the re-evaluation of the chemo-mechanical coupling comes from a simple question: for how long will the fundamental mechanical and hydraulic properties of materials of the barrier last unchanged, despite elevated temperatures that are known to activate mineralogical changes. Note that some mineralogical changes, such as dissolution of quartz or carbonates, or hydration of swelling minerals are recognized as leading to a substantial loss of strength and changes in overconsolidation ratio.

The above premises are sufficiently serious to trigger investigations into a chemical effects on strength, moduli, deformability and permeability of clays, and possibilities of their modeling. This paper focuses on the mechanical effects of long-term mineralogical changes in the clay mass near the contact with a magmatic intrusion at the natural analog site at Orciatico, Italy, and calibration of the thermo-chemo-plasticity model proposed earlier.

The mineralogical aspects of the Orciatico site are briefly described. Principal hypotheses on the reported mineralogical and geomechanical evolution are then discussed and the results of the thermo-mechanical tests on the samples from the site are reported. The identification of mechanisms and parameters for the constitutive model adopted are then described.

\section{Geomechanical natural analog at Orciatico site}

A number of studies were conducted on natural analogs where an intrusion of a hot magmatic body occurred into clay formation. The leading metamorphic mechanism in clays in the range of analog temperature has been identified as illitization of smectite in the upper Pierre Shale at Walsenburg, CO (Pytte and Reynolds, 1989), Murakami clay (Kamei et al., 1990) and in Kinnekulle clay (Pusch and Madsen, 1995). However, this mechanism does not seem to fit the findings at sites of Orciatico (Leoni et al., 1986) or Skye (Pellegrini et al., 1998).

While the interest in the above listed studies concentrated on mineralogical transformations per se, due to thermal impact, our perspective is from the geomechanical point of view. Our effort will focus on the understanding the long-term changes that may have been induced by heat in the two principal properties of clay: its mechanical deformability and strength, and permeability. It is postulated that such changes occur due to mineralogical evolution of the clay induced by the prolonged heating. There exists a sufficient experimental substantiation to the believe that strength, apparent overconsolidation and permeability and possibly other characteristics of soils are dependent on

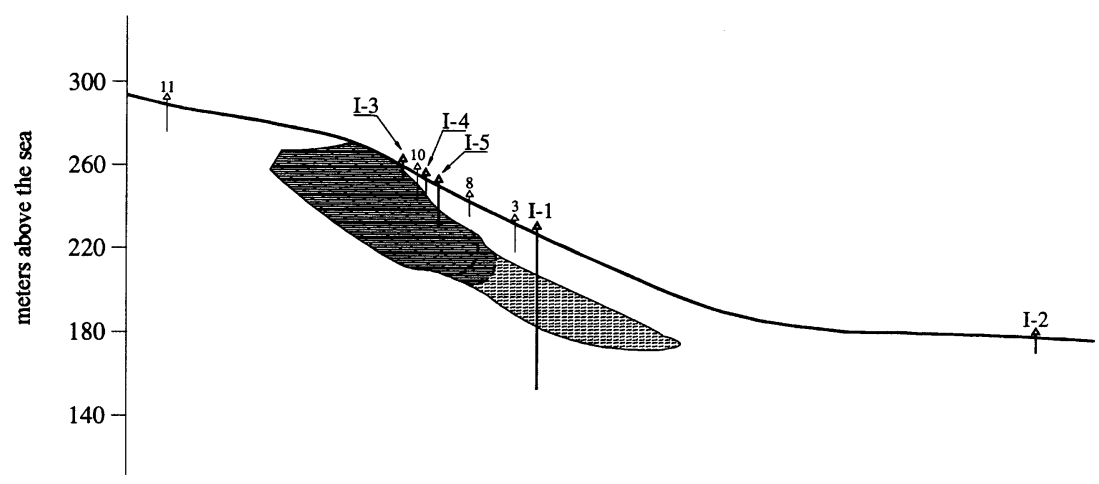

Fig. 2. Geologic cross-section and location of drillings as resulting from mineralogical analysis and geophysical survey (after Pellegrini et al., 1998). Darker shade demarks most recent assessment of the position and extent of the laccolith, as opposed to the previous evaluations (lighter shade). 
mineralogical content of clay, or at least that they change in correlation with the mineralogical changes (Murray and Quirk, 1990; De Olmo et al., 1996; Hueckel et al., 1998).

The site at Orciatico in western Tuscany, near Volterra, was thoroughly investigated in early 1980 s by ENEA of Italy (Leoni et al., 1986; Benvegnu et al., 1988). More recent studies on this analog are presented by Pellegrini et al. (1998). At this site, a Pliocene clay mass was penetrated by a main alkalitrachytic magmatic body at the temperature estimated to be around $800{ }^{\circ} \mathrm{C}$ at the main branch (Fig. 1). The understanding of disposition and extent and shape of the magmatic body has evolved as more data were collected using magnetometric surveys and geoelectric soundings (Rizzo, 1996). It is currently believed that in addition to the main lava body, a more modest intrusion in the form of a minor laccolith of a limited thickness has formed at the periphery, Fig. 2 (marked as "drilling B" in Fig. 1, where a gross mineralogical profile is also shown). Because of the small thickness and a peripheral location this body is thought to have experienced a lower temperature, not exceeding 400 ${ }^{\circ} \mathrm{C}$ at the contact with clay. Since this temperature is much more close to that expected in the waste repository conditions, this laccolith was selected for a focused analog study.

\section{Mineralogical evolution at the Orciatico site}

From the mineralogical point of view, the intrusion caused metamorphism of clay forming a halo of an indurated scaly shale, with distinct ranges of occurrence of thermally affected soils generically called selagite (volcanic), thermantite and (indigenous) clay, as proposed by Leoni et al. (1986). Three kinds of thermo-metamorphism are identifiable at the site: (i) crystallization of pyroxene, plagioclase and biotite, relatively localized at the contact with magma, (ii) crystallization a K-feldspar and (iii) crystallization of $\mathrm{K}$-smectite. The crystallization of smectite occurs over the entire metamorphic halo and involves only the fine size mineral grains. Macroscopically, three types of thermantite may be distinguished identified by their respective adjectives: hornfelic, spherulitic, and pseudogalestrian. Only the last type of thermantite (III), more distant location from the contact, is typical of the analog temperature range, even though in the peripheral locations it can also be found directly at contact with the magmatic body. In this range, lack of copresent pyroxene, $\mathrm{Na}-\mathrm{Ca}$ plagioclase and biotite suggests temperatures definitely lower than in other parts of the intrusion. Thermantite III is a gray, slightly baked clay, which is characteristically harder than the clay of reference, and very brittle, becoming a very fine paste upon slight stress. The peripheral locations were supposedly subjected to much faster cooling that the rest of the intrusion. Migration of chemical components in this zone, associated with thermal advection seems to be entirely confined within the zone. This indicates an essentially closed system, about 2-m thick, with a sharp boundary at the contact with unaffected clays.

From the point of view of physical alterations, a different zonation has been proposed (Leoni et al., 1986): (a) a zone $0.5-1.5$ to $3.0 \mathrm{~m}$ from the contact, of clay transformed in a very compact, scarcely fractured, re-crystallized material of low plasticity; (b) a zone more than 1.5 to $3.0 \mathrm{~m}$ distant of an intensely fractured clay material. It was suggested that a massive migration of interstitial water took place in the latter zone, followed by an extensive, diffuse micro-cracking. Cracking may have caused an increased permeability and vigorous convective water circulation. The intensified water flow in turn might have lead to accelerated cooling at the same time inducing a re-smectitization.

Because of the presumably lower temperatures, we will focus on a location immediately adjacent to the previous ENEA borehole S10 (Fig. 2). ISMES has performed a series of drillings in its vicinity yielding material from boreholes I5 and I4. This material and that from borehole I2 will be considered in what follows. The two former will be considered to have the same mineralogical profile as S10, while clay from borehole I 2 will be used as a reference material, that is, as thermally unaffected. It must be emphasized, that due to scarcity and simultaneously complexity of the field data the following considerations need to be treated as an example of applicability of the model, rather than a simulation of well understood changes at a specific site.

The average mineralogical composition of the indigenous clay at the top versus that of the thermally affected clay at the bottom $(-7.20$ to $-8.80 \mathrm{~m})$ of borehole S10 is given in Table 1. 
Table 1

ENEA borehole S10 (after Leoni et al., 1986)

\begin{tabular}{lll}
\hline Mineral & $\begin{array}{l}\text { In indigenous clay } \\
\text { (\% in weight) }\end{array}$ & $\begin{array}{l}\text { In the affected clay } \\
\text { (\% in weight) }\end{array}$ \\
\hline Quartz & $28-32$ & 20 \\
Plagioclase & 6 & 11 \\
K-feldspar & $2-3$ & 14.5 \\
Calcite & 14 & 14 \\
Smectite & 0 & 14.4 \\
Illite and & 37 & 26 \\
$\quad$ detrital micas & & 0 \\
$\begin{array}{l}\text { Illite/smectite } \\
\quad \text { interstratified }\end{array}$ & 5 & 0 \\
$\quad$ Vermiculite & 5 & 0 \\
Chloritic intergrades & 6 & \\
\hline
\end{tabular}

${ }^{\text {a }}$ Values averaged over the range -7.20 to $-8.80 \mathrm{~m}$.

The mineralogical profile for borehole S10 is presented also in Fig. 3. There is a clear pattern of mineralogical variability throughout the borehole. On the one hand, there is a visible plateau of the weight content of calcite, plagioclase, feldspar, quartz, $\mathrm{K}_{2} \mathrm{O}$, mixed layer, chlorite intergrades, and to a degree, illite and vermiculite above the depth of $-6.20 \mathrm{~m}$. On the other hand, a dramatic gradient in the content of pyroxene and $\mathrm{K}$-feldspar, usually associable with high temperature transformations, is present at the postulated interface between the volcanic intrusion of selagite and thermantite, located at -8.80 and $-9.20 \mathrm{~m}$. Another set of gradients in the content of clays: illite, smectite, vermiculite, intergrades, but also plagioclase, calcite and K-feldspar, associable with lower temperature transformations occurs at the depth between -6.30 and $-7.80 \mathrm{~m}$. At this location, the occurrence of thermantite III, or pseudogalestrian clay is reported. The effects of thermal and chemical changes will be investigated at the location of these gradients.

There are two major "unexpected" observations from the analysis of the Orciatico analog site conducted by ENEA (Leoni et al., 1986). The first one is of mineralogical nature. It regards an increase of smectite content attributed to the thermal cycle in a few-meter aureole around the intrusion, and lack of it in more remote locations. In borehole S10, between the depth of -6.20 and $-9.30 \mathrm{~m}$ the level of smectite content increases from $0 \%$ to the maximum of $25 \%$, whereas the illite content decreases from $35 \%$

Borehole S-10

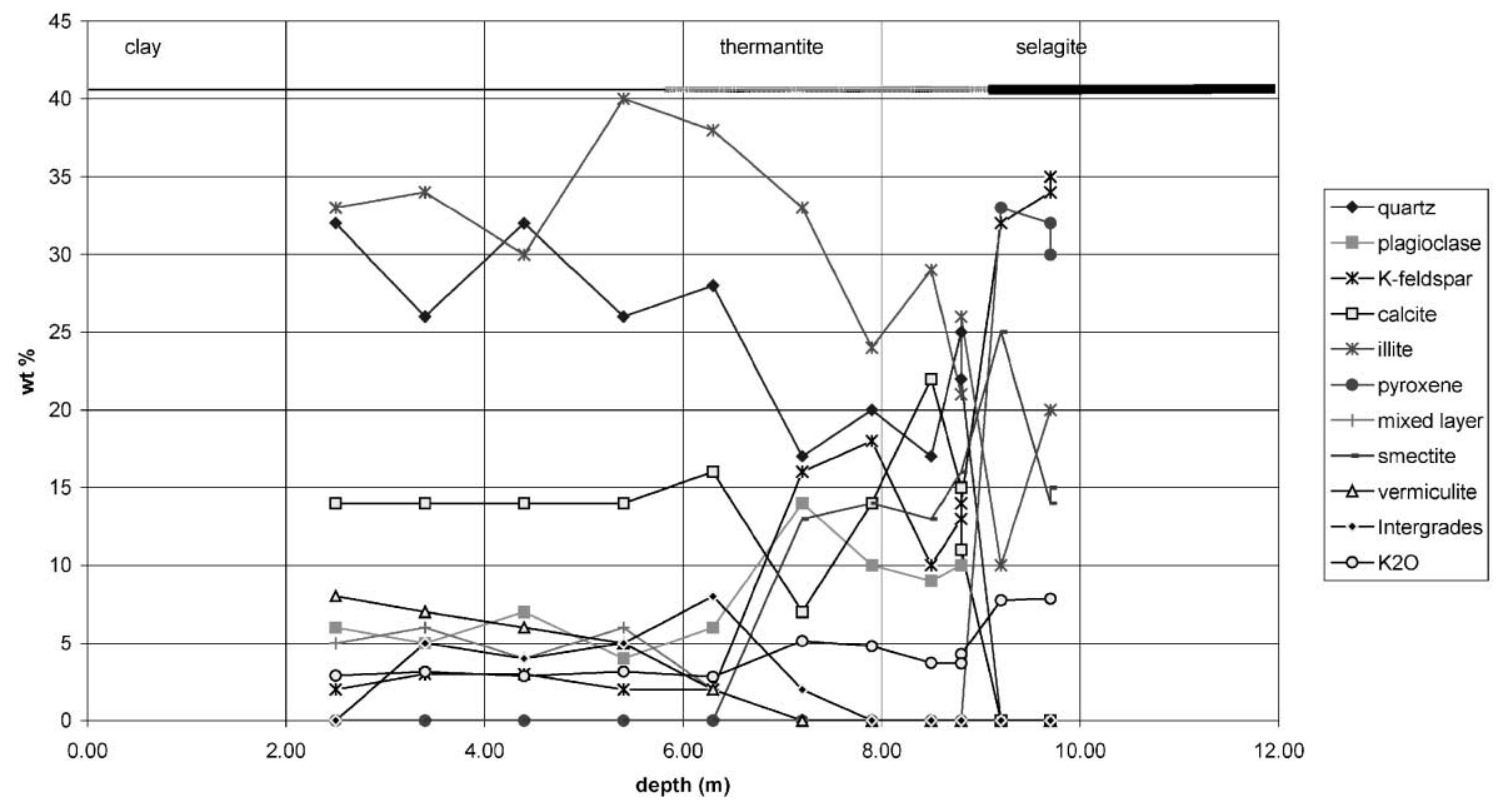

Fig. 3. Mineralogy of borehole ENEA S10 (following the data from Leoni et al., 1986; Benvegnu et al., 1988). 
to $18 \%$. This is confirmed by a clay exchange capacity, CEC, increase from 20 to 24 . Concomitant with these changes is the evolution in clay crystallinity, as seen in Fig. 4. Incidentally, the meaning of Illite Crystallinity Index (Weaver, 1960; Weber, 1972), used by evaluating the diminishing breath of the 10 - $\AA$ peak to measure a growing crystallinity of illite, has been re-evaluated recently. It is believed now (Weaver and Broekstra, 1984) that it rather reflects a simple amount composition of I/S component of the material. So it is not surprising that the gradient shown in Fig. 4 is coincident with the gradient of illite content from Fig. 3. A similar type of gradients in mineralogy was deduced by British Geological Survey at the Skye site, including by an increase in CEC from 45 to $70 \mathrm{meq} / 100 \mathrm{~g}$ (see Pellegrini et al., 1998). As already mentioned, this is an opposite trend to that seen at other analog sites, marked by development of illite on the base of the pre-existing smectite.

The other observation is of physico-mechanical nature, and refers to an increase in "hardness", con- comitant with an increase in "brittleness" of the clay that has presumably been thermally exposed. This clay reportedly becomes a very fine paste upon application of even a slight stress.

Leoni et al., 1986 have proposed the following scenario for the mineralogical transformations at Orciatico. They conclude that the direction of the reaction involving clays is opposite to the reaction of di-octahedral smectite into I/S and into illite, classically attributed to diagenesis and contact metamorphism. They suggest the mechanism of retro-morphosis of illite, the illitic component of the interstratified, vermiculite and chlorite minerals into smectite. They additionally propose that re-smectitization occurred when a thermally induced migration of interstitial water took place intensified by an extensive, diffuse micro-cracking.

Cracking, in their opinion, may have led to an increase in permeability. Cracking induced by dehydration/rehydration cycles has been observed in laboratory experiments by Murray and Quirk (1990). In the case of Orciatico clays, it is not certain whether the micro-fracturation was caused during cooling, or due

S-10 Illite cristallinity

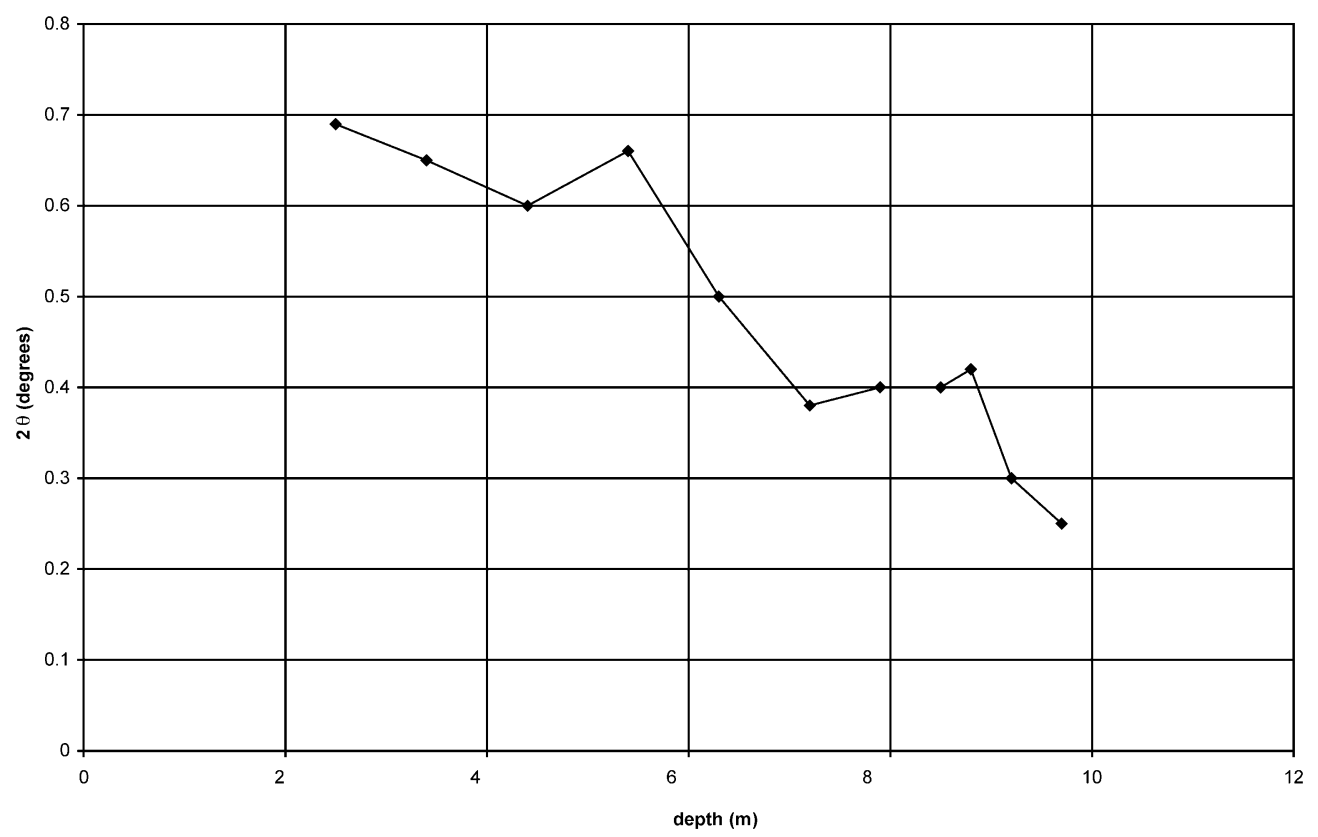

Fig. 4. Illite crystallinity index in borehole S10, following data of ENEA. 
to differential thermal expansion of solid and fluid phases during heating. Cracks are often filled with calcite, presumably much younger. The walls of the micro-cracks are lined by a thin layer of smectite. Such observations are consistent with the observations of Schoen and White (1965) and Steiner (1968) of alteration zones near fissures in which new mineral assemblages are formed close to the sites of circulating fluids. The re-smectitization was also noted for the French koalinitic/smectitic clay from Basin Parisien tested periodically for nearly 2 years at the site in Stripa Mine (Atabek et al., 1990).

In our analysis, we will follow the above scenario of Leoni et al. (1986). Given the fact that the zone of analogy is limited by the estimated temperature below $200{ }^{\circ} \mathrm{C}$, it is quite plausible that illitization have not occurred at all during the initial heating phase, or was entirely reversible in that zone. Indeed, laboratory experiments by Huang et al. (1994), seem to indicate that dehydration through an abrupt loss of one onemolecule layer of water does not occur in montmorillonite with initially three $\mathrm{H}_{2} \mathrm{O}$ layers, below the temperature of $350{ }^{\circ} \mathrm{C}$. Dehydration of another layer requires $490{ }^{\circ} \mathrm{C}$. However, rehydration and resmectitization, apparently occur at much lower temperatures and pressures. During rehydration, interplatelet distance versus temperature curve exhibited a large hysteresis. In fact, in a dehydrated montmorillonite with two interlayers of water, rehydration does not occur until the clay cools to $88{ }^{\circ} \mathrm{C}$ (with a jump in interplatelet distance from 15.33 to $16.55 \AA$ ), and then at $40{ }^{\circ} \mathrm{C}$ (with a jump from 16.55 to $17.75 \AA$ ) to a distance slightly smaller than the original three layers of water. An almost perfect reversibility was attained in that cycle. In a different test for a mineral with two initial $\mathrm{H}_{2} \mathrm{O}$ interlayers, rehydration seemed irreversible both for one interlayer configuration and for completely dehydrated material. A possible cause of the irreversibility may be a locked-in reconfiguration of the clay particle system, as suggested by $\mathrm{Wu}$ et al. (1997).

A mechanism alternative to the one-step rehydration is dissolution/precipitation proposed by Nadeau et al. (1985), Whitney and Velde (1993), Pusch and Madsen (1995) and Hetzel et al. (1994). In this reaction, clay particles composed of certain number of platelets break off, dissolve in water, acquire an adsorbed water layer, flocculate into larger clusters and eventually precipitate on solid substrate. This hypothesis is supported by the evidence of smectite coating of the internal walls of micro-fractures (Leoni et al., 1986).

Independently of the mechanism considered, the overall reaction in the range of analog may be described as follows (see also Table 1):

$$
\begin{aligned}
\text { quartz } & + \text { calcite }+ \text { phillosilicates }(\text { non }- \text { smectitic) } \\
& + \text { alkalis (from magma and phillosilicates) } \\
& \rightarrow \text { smectite }+\mathrm{K}-\text { feldspar } \\
& +\mathrm{Na}-\text { plagioclase }
\end{aligned}
$$

Specific steps of this reaction are not known. It is suggested that dissolution of quartz contributes to the formation of albitic plagioclase and potassium feldspar, whereas illite (but also basalt) releases potassium used in the formation of feldspars.

As dominant reactions, from the point of view of the influence of the chemical reaction on mechanical properties, we will consider recrystallization of smectite and transformation of quartz. The latter one, without any doubt could lead to weakening of soil. However, quartz is believed to have contributed to formation of feldspar and plagioclase, with a marginal mass content change (an increase from $41 \%$ to $44.5 \%$ ). Since quartz and feldspar and plagioclase have comparable strength (Kowalski, 1974), a limited contribution to the overall estimated loss of strength is expected from quartz to feldspar/plagioclase metamorphosis. By far most important, also numerically, is the reaction involving clays. This reaction may be represented as

$$
\begin{aligned}
\text { (illite } & + \text { vermiculite }+ \text { chlorite intergrades } \\
& +\mathrm{I} / \mathrm{S} \text { mixed layers })+ \text { water } \\
& \rightarrow \text { smectite (including adsorbed water) } \\
& + \text { potassium }
\end{aligned}
$$

In what follows, we will confine our interest to the above clay transformation only, and consider the other reactions as of limited contribution to the mechanical changes. Hueckel (2002) analyzed the reaction of clay rehydration as a thermodynamic process. He considered several possible representations of dehy- 
drating clay as open or closed thermodynamic systems. He suggested that given the nature of the involved processes, as they are currently understood, and a limited quantitative information, a two-phase system could be considered, as shown in Fig. 5. The liquid phase comprises stagnant water only. The solid phase is composed of the solid mineral skeleton and interplatelet (adsorbed) water. The free (flowing) water is assumed to be confined to the micro-fracture network, and thus be a part of the surroundings, and not of the system. By the concept of superimposed continua, it should be reminded that each material point contains the solid and (stagnant) water. Each phase is composed of a number of species. In a simplified approach, four species contributing to the total change in the specific mass of the system during the reaction can be identified. These are: the original clay minerals, enclosed in the parenthesis in the left hand side of Eq. (2), and called for brevity illite for its dominant component and stagnant water, for reactants, and smectite solids, adsorbed water, and potassium, being products. The total mass exchange rate, $\mathrm{d} c$, split into the part internal to the system, $\mathrm{d}_{\mathrm{i}} c$ and the external one, $\mathrm{d}_{\mathrm{e}} c$, would then read

$\mathrm{d} c=\mathrm{d}_{\mathrm{i}} c+\mathrm{d}_{\mathrm{e}} c$

$\mathrm{d}_{\mathrm{i}} c=\mathrm{d} c^{\mathrm{ill}}+\mathrm{d}_{\mathrm{i}} c^{\mathrm{sw}}+\mathrm{d}_{\mathrm{i}} c^{\mathrm{K}}+\mathrm{d} c^{\mathrm{sm}}+\mathrm{d} c^{\mathrm{aw}}$

$\mathrm{d}_{\mathrm{e}} c=\mathrm{d}_{\mathrm{e}} c^{\mathrm{sw}}+\mathrm{d}_{\mathrm{e}} c^{\mathrm{K}}=\left(-\frac{1}{\rho^{\mathrm{sw}}} J_{i, i}^{\mathrm{sw}}-\frac{1}{\rho^{\mathrm{K}}} J_{i, i}^{\mathrm{K}}\right)$

where $c^{k}$, is defined by its mass fraction as $c^{k}=\left(\rho^{k} / \rho\right)$; $\sum_{k} c^{k}=1$ and $\rho$ is a total specific mass of the solid or fluid phases per unit element volume of soil. The mass concentration of the species is identified by the superscripts, with "aw" and "sw" standing for adsorbed water and stagnant water, respectively, "ill" and "sm" for illite and smectite, whereas " $\mathrm{K}$ " for free potassium ion, respectively. $J_{i}^{k}$ is $i$-th component of the mass flux of $k$-th species. Note that two first terms of the right-hand side of Eq. (3) are negative.

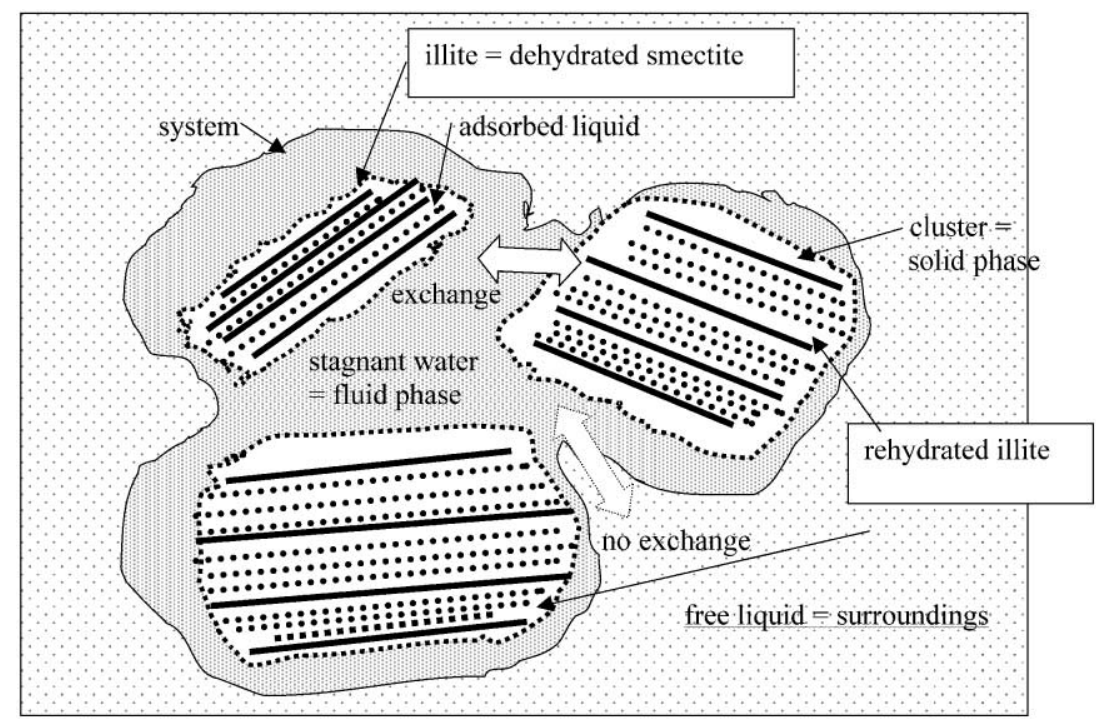

Fig. 5. Schematic of a representative elementary volume for re-hydrating clay. It is a two-phase system consisting of the solid skeleton, adsorbed water, as one phase and a fraction of free water defined as stagnant (not adsorbed, but with zero velocity, trapped) water (Van Genuchten and Wierenga, 1976), as a second phase. The remaining, freely flowing water is outside the system. This is equivalent to say that during rehydration there was enough water in the surroundings that flow of this water may be neglected. The exchange of mass is limited to the two former water components or cations contained within them. Thus, even if the system is in principle open, the actual exchange of species is internal to the system. Therefore, in effect the system can be considered as closed. This presents a number of advantages, and is defendable on the physical basis. In essence, such formulation corresponds to Biot's (1977) soil hypersystem. 
In two possible representations of the metamorphism mechanisms considered before, in the first one, rehydration of the clay mineral interplatelet space, the emphasis is on water mass transfer from the liquid to solid phase (from stagnant to adsorbed water). In the second mechanism, more oriented at, but not limited to, the dissolution/precipitation reactions, the focus is on mass changes of the global mineral species involved (illite to smectite kinetics).

Currently available data for the Orciatico site, allow us to consider only the second mechanism. In addition it is assumed that both dissolution and precipitation occur on a local scale, i.e. within the REV. Thus, no transport of dissolved species, or an intermediate mineral product is involved outside of the system. This is consistent with the field observation of Leoni et al. (1986) that there was no material transport outside of thermantite zone III. Furthermore, based on the experimental findings of Low (1987), the water content during swelling is assumed as a linear function of the mass of the clay mineral available. While it is realized that Low's experiments simulated clay re-hydration from a dry state, and not necessarily need to reflect the situation of re-smectitization of compacted illite considered here, we shall follow this hypothesis. Thus, the mass balance equation (Eq. (3)) is reformulated as

$-\left(\mathrm{d} c^{\mathrm{ill}}+\mathrm{d} c^{\mathrm{sw}}\left(\mathrm{d} c^{\mathrm{ill}}\right)\right)=\mathrm{d} \tilde{c}^{\mathrm{sm}}$

where

$\mathrm{d} \tilde{c}^{\mathrm{sm}}=\mathrm{d} c^{\mathrm{sm}}+\mathrm{d} c^{\mathrm{aw}}$

is a global measure of the change in specific mass of smectite, including adsorbed water. Therefore, the mass balance is restricted to the mineral transformations only. The exchanges with the environment, in terms of the stagnant water and potassium, are neglected. Such an approach is quite common in geochemistry because of uncertainties arising about the actual course of many mineralogical transformations. This leads to a practice in reactive transport modeling to employ empirical reaction rate formulas (Oelkers, 1996). In particular, we shall employ a kinetic reaction equation adapting the original formulation for illitization (or) dehydration by Pytte and Reynolds (1989).

$\frac{\mathrm{d} \xi^{\text {ill }}}{\mathrm{d} t}=-\frac{\mathrm{d} \tilde{c}^{\mathrm{sm}}}{\mathrm{d} t}=k(\mathrm{~K} / \mathrm{Na})^{b}\left(\tilde{c}^{\mathrm{sm}} \theta^{(\mathrm{M})} \omega\right)^{a}$ where

$S=\tilde{c}^{\mathrm{sm}} \theta^{(\mathrm{M})} \omega$

is the mole fraction of smectite in the entire clay fraction, which is believed to contribute to re-smectitization, including smectite itself, illite, I/S, vermiculite and chlorite intergrade, while $\theta^{(\mathrm{M})}$ and $\omega$ are the ratio of molar masses of smectite and total clay fraction, and clay content, respectively. Exponent $a$ is the degree of the reaction, while $k$ is the rate constant defined through the Arrhenius equation

$k=A \exp \left(-\frac{U}{R T_{\mathrm{K}}}\right)$

and $U$ is the activation energy for the reaction, $R$ is the gas constant and $T_{\mathrm{K}}$ is absolute temperature. $A$ is the frequency factor.

For re-smectitization, following Hueckel (2002), we postulate by analogy to Eq. (5) that

$\frac{\mathrm{d} \xi^{\mathrm{rs}}}{\mathrm{d} t}=\frac{\mathrm{d} \tilde{c}^{\mathrm{sm}}}{\mathrm{d} t}=k\left(1-\tilde{c}^{\mathrm{sm}} \theta^{(\mathrm{M})} \omega\right)^{a}$

Note that in difference to the original Pytte-Reynolds equation (Eq. (5)), the component relative to potassium has been dropped from Eq. (7). In fact, the amount of potassium available does not play in rehydration any role, as opposed to that it plays for illitization. Pytte and Reynolds determined experimentally, that the order of dehydration reaction is $a=5$. It should be emphasized that by assuming the same kinetics for the reverse reaction (except for the omission of potassium in Eq. (7)), as used for the direct reaction, implies the same temperature dependence, and theoretically no hysteresis. Due to the lack of direct data from rehydration experiments, the constants for the dehydration branch of the hysteresis may be considered. Following Pytte and Reynolds (1989), $A=5.2 \times 10^{7} 1 / \mathrm{s}, U=33 \mathrm{kcal} /$ mol.

It is interesting to note that Pusch and Karnland (1996) used Eq. (5) to predict the advancement of smectite to illite conversion over the period of a possible life-time of a bentonite based nuclear waste buffer. They found that in realistic conditions of potassium supply, even in a hypothetical evolution of the site into a marine environment the rate of conversion would be 
insufficient to produce meaningful changes. This however is not necessarily the case for an inverse reaction of re-smectitization, which does not depend on any external supply (except water), and in particular that of potassium.

We will additionally assume that the mineralogical reaction of clay re-hydration did not start at Orciatico site until late in the post heating stage, (during cooling), that is when water saturated the system. This means that the system reached saturation within stagnant water, and thus, a mechanical and hydraulic equilibrium. Initial chemical equilibrium is also assumed between flowing water and stagnant water, but not between the former one and the solid phase.

\section{Chemo-plasticity characterization of the chemical softening due to rehydration of clay at Orciatico}

Numerous experiments show that clays exhibit thermal softening due to heating below water boiling point (e.g. Hueckel et al., 1998), chemical softening or chemical hardening, depending on chemical reactions or chemo-physical processes involved (Hueckel, 1992, 1997). As a result, it is feared that strength, and maximum apparent precompression stress could be significantly reduced during the heating phase of waste disposal. To characterize possible adverse effects of long-term mineralogical reactions, it was proposed that such effects could be detected by analyzing the history of thermal and possibly chemical loading of clay at Orciatico site using the reactive chemoplasticity model, described by Hueckel (2002). As with previous thermo-plasticity Cam-clay model described by Hueckel and Borsetto (1990), we postulate that there is only one hidden hardening variable, $p_{\mathrm{c}}{ }^{\prime}$, which defines the size of the current yield surface in terms of isotropic effective stress. The rate of change of this size is assumed to be a function of the plastic strain rate, temperature rate and the rate of chemical reactions (Hueckel, 2002). The only chemical (mineralogical) reaction that is assumed to cause variations of the mechanical properties of clays is resmectitization of the illite-vermiculite-intergradeI/S mixed layer complex. The variable that is used to quantify reaction progress is the weight amount of neo-formed smectite per total weight of the soil, or smectite content in the illite-vermiculite-intergrade$\mathrm{I} / \mathrm{S}$ mixed layer complex, $\xi^{\mathrm{rs}}$, as defined through its evolution equation (Eq. (7)).

The mechanical properties that are assumed as depending on the reaction progress are: yield surface, elasticity moduli, and chemical strain. However, since the data from the analog by its very nature refer to irreversible changes only, only the changes in the yield limit can be quantified.

The dependence of the yield limit on the reaction progress is expressed through the size of the yield surface defined as follows

$$
\begin{aligned}
p_{\mathrm{c}}^{\prime}= & p_{\mathrm{c} 0}^{\prime}\left[(\lambda-\kappa)^{-1}\left(1+e_{0}\right)\left(\varepsilon_{\mathrm{v}}^{\mathrm{pl}}\right)\right] \\
& +2 A(\Delta T)+2 B\left(\xi^{\mathrm{rs}}\right)
\end{aligned}
$$

where $A$ and $B$ are, respectively, thermal and chemical hardening/softening functions,

$A=a_{1}(\Delta T)+a_{2}(\Delta T)^{2}$

$B=b_{1} \xi^{\mathrm{rs}}+b_{2}\left(\xi^{\mathrm{rs}}\right)^{2}$

Note that additivity of the strain, temperature and chemical portions of the hardening function (Eq. (8)) is not the only way in which these three hardening terms could be combined. An alternative is a product of the three terms within the exponential function as discussed by Hueckel et al. (1999) or an environmental hardening factor multiplying the exponential function of plastic volumetric strain (Hueckel, 1992). Each of these three cases has different implications in terms of plastic modulus at constant environmental conditions, and strain additivity.

\section{Identification of constants for chemo-plasticity model}

To fully characterize the model for the Orciatico site, the following parameters need to be determined: (i) isothermal, bulk $(\kappa)$ and shear $(G)$ elastic moduli, and plastic bulk modulus $(\lambda)$; (ii) initial apparent maximum precompression vertical $\left(\sigma_{\mathrm{v}}{ }^{\max }\right)$ or isotropic $\left(p_{\mathrm{c} 0}\right)$ stress; (iii) thermo-elastic expansion coefficients, $\alpha_{i}$, and thermo-plastic coefficients $\left(a_{i}\right)$; (iv) chemo-plastic coefficients $\left(b_{i}\right)$. The strategy to eval- 
uate parameters of the thermo-chemo-mechanical model described above is as follows. First, the purely mechanical coefficients (as in (i), (ii), and (iii)) will be evaluated for specimens unaffected by any thermal history, that is with $A=B=0$. For that purpose samples from a location (borehole I2) remote from the heating site were tested. Borehole I2 is considered as a representative of background material. In addition, the material from low temperature end of borehole I4, that is relatively shallow locations, was considered as representing reference material.

Subsequently, samples from the unaffected borehole I2 were tested for their thermo-mechanical shortterm response, with the purpose to identify thermoelastic and thermo-plastic constants, (iii). Finally, from the affected zone in borehole I4, sample were selected at locations presumably corresponding to specified maximum temperature points and tested for their apparent maximum precompression vertical stress $\left(\sigma_{\mathrm{v}}^{\prime}{ }^{\max }\right)$ in oedometers. Reconstructing hypothetical mechanical, thermal and mineralogical history of these specimens, chemical softening parameters (iv) were recovered.

The mechanical moduli, $\kappa$ and $\lambda$ are determined from the mechanical isotropic loading processes on sample CR2 from a location at depth $-2.51 \mathrm{~m}$ in borehole I2. The specimen was relatively porous $(e=0.654, w=21 \%)$. This specimen was also used for thermal tests. Although the thermal cycles may have an effect of the mechanical moduli, at this point no numerical evaluation may be given to this. The elastic logarithmic isotropic modulus, $\kappa$, is obtained from the unloading from 0.8 to $0.3 \mathrm{MPa}$ and subsequent reloading within the same limits. Taking the initial void ratio as after completion of saturation, $e_{0}=0.605$, one obtains the values of $\kappa=0.0217$ and 0.0268 , and the average 0.0243 . The plastic logarithmic isotropic modulus, $\lambda$, is obtained from the plastic loading between 0.8 and $1.5 \mathrm{MPa}$. With strain of $0.0152, \lambda=0.0388$. The latter value is relatively low for clays.

\section{Thermo-mechanical characterization}

The tests consisted of generation of thermal strains at different isotropic stress values during heating and cooling. The objective of the tests was to generate data on short-term thermal sensitivity of the yield surface at isotropic stress conditions. The test was conducted on a specimen that has not previously been subjected to thermal history at the site. The motivation of this choice was the need to identify difference between long-term and short-term thermal effects on clay. The tests were conducted in drained conditions at the following values of isotropic stress: $0.3,0.8$, and 1.5 MPa. The specimen CR2 from borehole I2 has been described above. After saturation at $0.25 \mathrm{MPa}$, the specimen was loaded isotropically to $0.8 \mathrm{MPa}$ and subsequently unloaded to $0.3 \mathrm{MPa}$. At this stress value, the specimen was heated to $92{ }^{\circ} \mathrm{C}$ with the rate of $1.5{ }^{\circ} \mathrm{C}$ per $\mathrm{h}$, to ensure no pore pressure generation, and cooled back to $22{ }^{\circ} \mathrm{C}$. Subsequently, the specimen was loaded to $0.8 \mathrm{MPa}$, heated and cooled. The third cycle included loading to $1.5 \mathrm{MPa}$, heating and cooling. The results in terms of axial strain development, and volumetric strain development during heating are presented in Fig. 6. The volumetric strain of the porous skeleton are calculated, taking into account thermal expansion of pore water, and of the solid (see Baldi et al., 1988).

The axial strain exhibits expansion tendency during the first heating, and markedly much higher contraction during the two subsequent thermal cycles. Since the specimen was preloaded to $0.8 \mathrm{MPa}$ before the first heating cycle, it may be believed that the process occurred entirely as thermo-elastic. However, while the axial strain shows a moderate strain hysteresis, and virtually no irreversible strain upon completion, the volumetric strain exhibits a permanent tensile strain of $0.5 \%$, therefore attributable to an expansive lateral strain. Such expansion is attributed to a differential expansion of the non-homogeneous soil components.

Strains during heating and cooling at 0.8 and 1.5 $\mathrm{MPa}$ are very similar one to another. However, it must be noted that at $1.5 \mathrm{MPa}$, there was a substantial time delay with the completion of the deformation at $92{ }^{\circ} \mathrm{C}$. If this effect is taken into account, the $1.5-\mathrm{MPa}$ heating would show final volumetric strain over $0.25 \%$ higher. The irreversible strain in the first case amounted to $0.5 \%$, and in second $0.75 \%$. These strains are visibly lower than the corresponding three times axial strains, shown also in Fig. 6 suggesting an anisotropy of the process (see Hueckel and Pellegrini, 1996). Strains developed during cooling are all very 
ORCIATICO

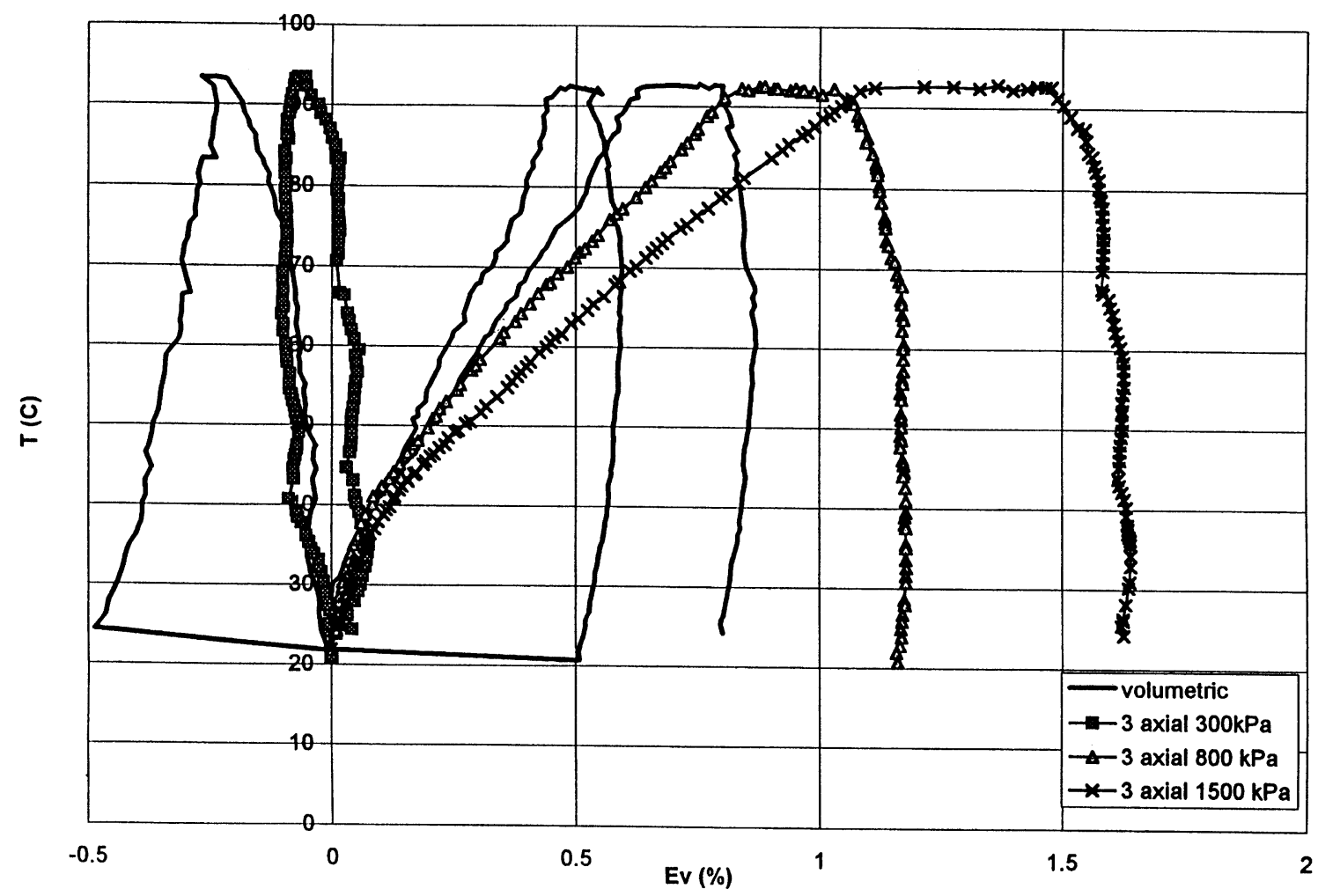

Fig. 6. Development of axial strain and volumetric strain (positive in compression) during heating of previously thermally unaffected clay from borehole I2. The volumetric strain of the porous skeleton is calculated, taking into account thermal expansion of pore water considered as free and at no pressure, and of the solid.

similar in the three cases, suggesting purely elastic response. It is believed (see Hueckel and Borsetto, 1990) that heating resulting in compressive irreversible strain is thermoplastic in nature and results in a major reduction of apparent preconsolidation stress, or in general a shrinking of the yield surface. The observed behavior is generally similar to that of other materials (from Boom, or Pontida sites) tested in the past (Hueckel and Baldi, 1990; Baldi et al., 1990). From the point of view of the specific values, the Orciatico material is closer to Pontida (which is an illitic clay) than to Boom (smectitic) clay, which exhibited about $2 \%$ of volumetric thermal strain at the stress near its normal consolidation state.

Thermo-elasticity and thermoplasticity coefficients are determined following a procedure established earlier (Baldi et al., 1988; Hueckel et al., 1998). Thermo- elasticity coefficients can be determined from thermal strain, which is simulated by the following equation (for which compressive strain is taken as positive)

$$
\begin{aligned}
\varepsilon_{\mathrm{v}}^{\mathrm{te}}= & {\left[\frac{\kappa}{1+e_{0}}+\left(\alpha_{1}+\alpha_{3} \Delta T\right) \Delta T\right] \ln \frac{p^{\prime}}{p_{\mathrm{g}}^{\prime}} } \\
& +\left(\alpha_{0}^{*}+\alpha_{2} \Delta T\right) \Delta T
\end{aligned}
$$

The coefficient of thermal expansion of the skeleton solids is assumed as $\alpha_{0}^{*}=10^{-5}{ }^{\circ} \mathrm{C}$. The variables $p^{\prime}$ and $p_{\mathrm{g}}$ are current and in situ effective isotropic stresses. The latter are evaluated on the basis of the in situ vertical stresses and the lateral ones on the assumption $\sigma_{2}=K_{0} \sigma_{1}$, with $K_{0}=0.5$, obtaining for the given depth $p_{\mathrm{g}}=0.17 \mathrm{MPa}$. The heating branch for the test at $0.3 \mathrm{MPa}$ and cooling branches for the 


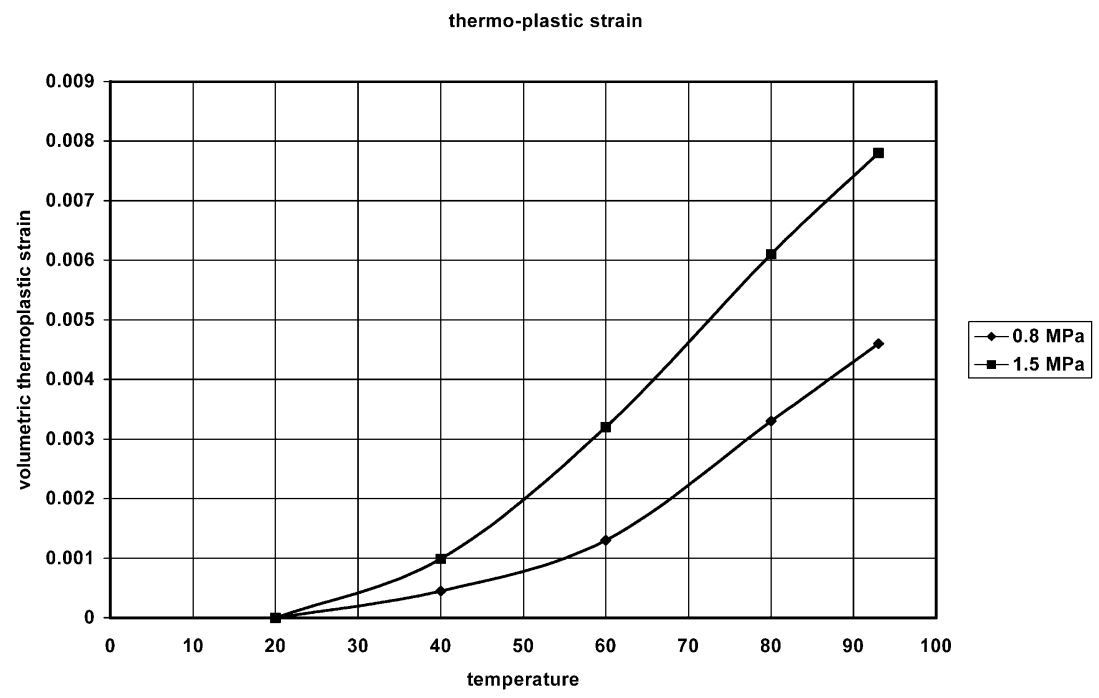

Fig. 7. Values of the plastic volumetric strain of Orciatico clay from borehole I2 during heating at constant stress of 0.8 and $1.5 \mathrm{MPa}$.

other tests are taken for calibration in understanding that no irreversible structural changes happened during these processes. The differences between these branches are attributable to the effect of the isotropic pressure sensitivity. The resulting coefficients are:

$\alpha_{1}=3.697 \times 10^{-5}\left[{ }^{\circ} \mathrm{C}\right]^{-1}$;

$\alpha_{2}=-1.20 \times 10^{-6}\left[{ }^{\circ} \mathrm{C}\right]^{-2}$ and

$\alpha_{3}=-3.21 \times 10^{-7}\left[{ }^{\circ} \mathrm{C}\right]^{-2}$.

It may be noted that strains during cooling at 0.3 and $0.8 \mathrm{MPa}$ are relatively small, and thus the stress dependent term has a relatively minor impact on the overall strain. This is similar to other natural clays tested in the past, as opposed to remolded clays.

Thermoplastic behavior is characterized by a thermal softening part of the hardening function defining the current value of the apparent maximum preconsolidation stress ( $\left.p_{\mathrm{c} 0}^{\prime}\right)$ Eqs. (8) and (9) with function $B\left(\xi^{\mathrm{rs}}\right)$ a priori set to zero. Thermal softening is determined through coefficients $a_{1}$ and $a_{2}$ which are calculated on the basis of the consistency equation for a constant stress at normal consolidation

$\frac{\mathrm{d} \varepsilon_{\mathrm{v}}^{\mathrm{pl}}}{\mathrm{d} T}=\frac{-\frac{\partial p_{\mathrm{c}}^{\prime}}{\partial T}}{\frac{\partial p_{\mathrm{c}}^{\prime}}{\partial \varepsilon_{\mathrm{v}}^{\mathrm{p}}}}$ which leads to

$$
\begin{aligned}
1 / 2 \partial p_{\mathrm{c}}^{\prime} / \partial T & =a_{1}+2 a_{2} \Delta T \\
& =-\left(\mathrm{d} \varepsilon_{\mathrm{v}}^{\mathrm{pl}} / \mathrm{d} T\right)\left(p_{\mathrm{c}}^{\prime} /[2(\lambda-\kappa)]\right.
\end{aligned}
$$

This identification requires the evaluation of plastic volumetric strain at the two confining stresses at which the plastic strain is generated, i.e. at 0.8 and 1.5 $\mathrm{MPa}$. The values of the thermoplastic strain are shown in Fig. 7.

Then, the values of the derivatives $\mathrm{d} \varepsilon_{\mathrm{v}}^{\mathrm{pl}} / \mathrm{d} T$ on rhs of Eq. (12) for the two isotropic stresses can be determined. Taking the plasticity modulus $\lambda-\kappa=0.0171$, and the appropriate $p_{\mathrm{c}}^{\prime}$, the values of the variable $1 / 2$ $\partial p_{\mathrm{c}}^{\prime} / \partial T$ are calculated as average for both isotropic stresses.

\begin{tabular}{llllll}
\hline $\mathrm{d} \varepsilon_{\mathrm{v}}^{\mathrm{pl}} / \mathrm{d} T$ & \multicolumn{5}{l}{$1 / 2 \partial p_{\mathrm{c}}^{\prime} / \partial \mathrm{T}$} \\
\hline$T / p_{\mathrm{c}}^{\prime}$ & 0.8 & 1.5 & 0.8 & 1.5 & Average \\
$\left({ }^{\circ} \mathrm{C}\right)$ & $\mathrm{MPa}$ & $\mathrm{MPa}$ & $\mathrm{MPa}$ & $\mathrm{MPa}$ & \\
\hline 40 & 0.8 & 1.0 & 0.0187 & 0.0438 & 0.0313 \\
60 & 1.1 & 1.4 & 0.0257 & 0.0614 & 0.0436 \\
80 & 1.0 & 1.4 & 0.0233 & 0.0614 & 0.0424 \\
\hline
\end{tabular}

It is clear that thermal hardening depends on the value of the confining stress, or accumulated plastic strain. 
It is also clear that the non-linearity of the hardening function is stronger than quadratic. Given these reservations, the values of thermal softening parameters is still calculated assuming the stress independence of the former, as

$a_{1}=-1.81 \times 10^{-2} \mathrm{MPa} /{ }^{\circ} \mathrm{C}$,

$a_{2}=-2.37 \times 10^{-4} \mathrm{MPa} /{ }^{\circ} \mathrm{C}^{2}$

The above parameters characterize the thermomechanical response of Orciatico clay, unheated by the lava intrusion, within the model previously discussed, but with $B=0$ and with the above indicated reservations.

\section{Calibration of the material exposed to long-term heating/cooling cycle}

Calibration of the long-term exposed materials was planned to be performed on the basis of oedometric test results on specimens from boreholes I1, I2, I4 and I5.
As it is concluded on the basis of the geognostic data, these boreholes were differently affected by heat. Borehole I1 was presumably affected by an intrusion of a limited layer of volcanic material less than a meter thick, borehole I2 was not at all thermally affected, borehole I4 was intersected by a limited basalt layer of about 2-3-m thick, whereas borehole I5 with a few meter layer.

The latter two boreholes are believed to have their mineralogical profiles similar to that of hole S10 shown in Fig. 3, due to horizontal distances of about 1-2 m and about $10 \mathrm{~m}$. The data of the values of apparent maximum vertical pre-compression stress, obtained from the oedometric tests, plasticity index and void ratio for borehole I4 are superposed on the together with the mineralogical profile for ENEA borehole S10 in Fig. 8. In this figure, the scales of depth have been shifted over few tens of centimeters for I4 data with respect to the fragmentary information about the topographic (vertical) difference between the top of I4 and $\mathrm{S} 10$ boreholes. The shift was proposed to match the distinct location of the visible apparent pre-compres-

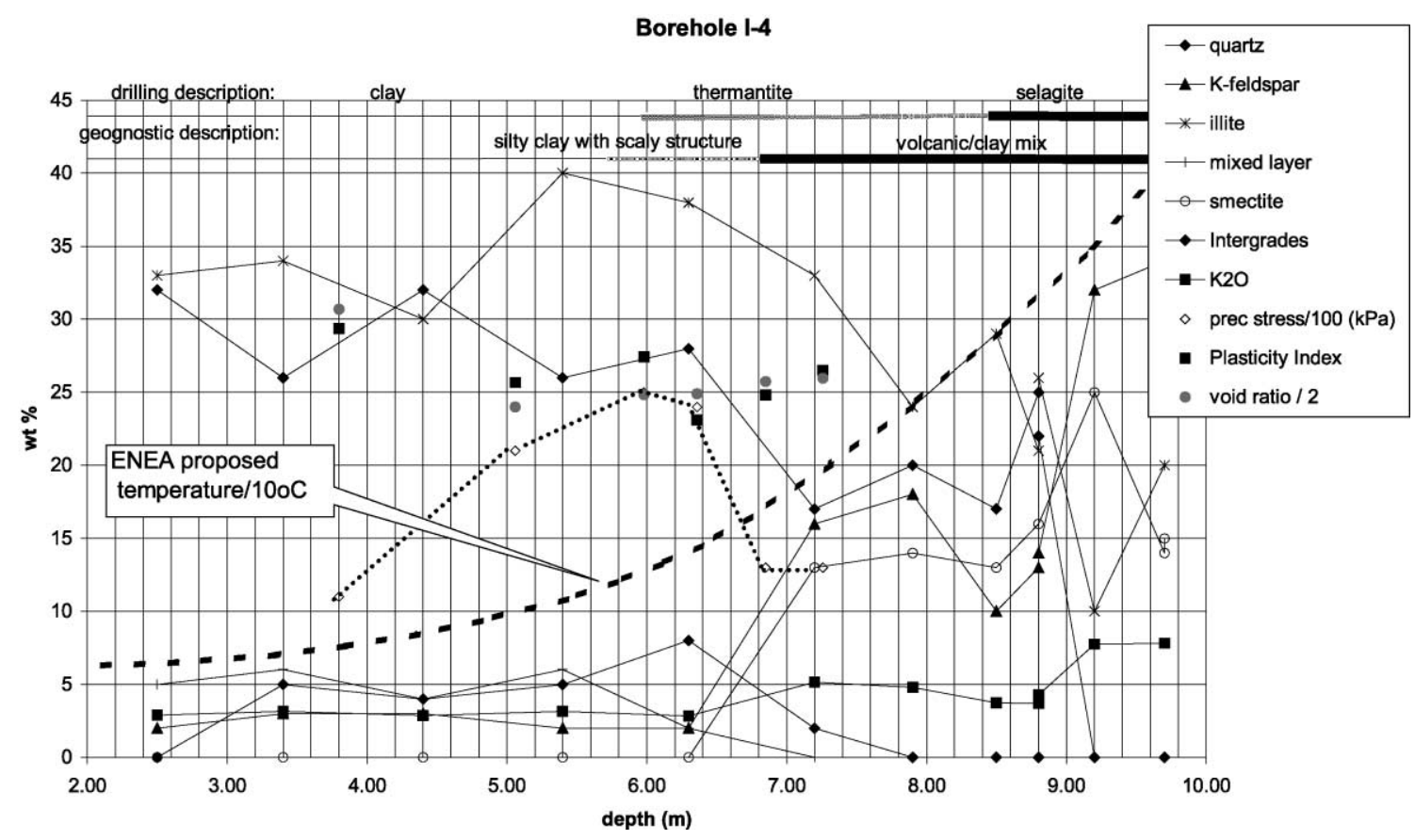

Fig. 8. Combined data on mineralogy of borehole S10 and data on the apparent maximum preconsolidation stress for borehole I4, with the superposed data on void ratio, plasticity index and estimated temperature distribution. 
sion gradient with the location of equally clear mineralogical gradient at -6.20 and $-7.10 \mathrm{~m}$.

One of the primary issues is the distribution of the maximum temperature reached during the intrusion process. Benvegnu et al. (1988) estimated the temperature distribution on the basis of certain transformations, such as generation of pyroxene, or plagioclase. In the resulting graph, reproduced in Fig. 8, a temperature of about $130{ }^{\circ} \mathrm{C}$ is suggested to have occurred at the interface between thermantite and clay, at $380 \mathrm{~cm}$ from the contact with selagite, to which temperature of 400 ${ }^{\circ} \mathrm{C}$ is attributed. The same authors in ENEA Report (1983) underline that borehole S10 which has nearly the same selagite thickness of $340 \mathrm{~cm}$, is atypical by being in contact with a peripheral apophysy of the intrusion, with a much lower temperature that other contacts in the zone. They suggest that the metamorphosed zone is only $2-\mathrm{m}$ thick, which leaves $1.40 \mathrm{~m}$ of the non-metamorphosed thermantite. It is thus concluded that the temperature distribution visualized by Benvegnu et al. (1988) refers to S10, since there is no other borehole in their report with a similar thermantite thickness. This is believed to apply also to the matched I4/S10 profile in Fig. 8. Thermantite (in the classification of ENEA) occupies the depth $5.8-9.2 \mathrm{~m}$, of which the zone 7.2 to $9.2 \mathrm{~m}$ is metamorphosized as clearly indicated by mineralogical content compared to that in the top soil. This zone is qualified in geognostic analysis (Rizzo, 1996) as volcanic rock/argillite mixture. The narrow zone between -5.8 and $-7.2 \mathrm{~m}$ corresponding to the zone of high gradients of mineralogical profiles, in geognostic profile is identified as "hard scaly clay". All the above statements seem to indicate that the material in the zone between -6.2 and $-7.2 \mathrm{~m}$ in I4 is what is termed as thermantite III or "pseudogallestrine". If this is the case, the paleotemperature distribution is quite uniform within the zone above $-6.5 \mathrm{~m}$ as sketched in Fig. 8, and reaching about $50-60{ }^{\circ} \mathrm{C}$ at the present surface. Thus, the zone of the thermal analog practically extends between $-6.5 \mathrm{~m}$ and 0 , and comprises the hard scaly clay or thermantite III and sandy-silty clay, showing no alteration of its mineralogy.

Given the above, most of the mineralogical transformation including re-smectitization does not affect the zone of the analog. This is enhanced by the conviction of Leoni et al. (1986) that many of the mineralogical effects were caused by the pressure and concentration of magmatic fluids, clearly with no analogy to nuclear waste disposal. This apparently includes the presence of potassium, in part linked to the presence of neo-smectite and the release from basalt.

In regard to the distribution of the apparent maximum precompression stress, $\sigma_{\mathrm{v}}{ }^{\max }$ (Fig. 9) obtained in oedometric tests, the following observations are made. The values $\sigma_{\mathrm{v}}{ }^{\max }$ for the original unaffected "reference" clay is taken as equal to $1050 \mathrm{kPa}$, being a mean value for the data from boreholes I2 and I1 unaffected range, as well as near surface specimens from I4 and I5. This stress corresponds to the hypothetical weight of about $150 \mathrm{~m}$ of a removed overburden saturated with water. The three specimens located slightly below have a clearly higher $\sigma_{\mathrm{v}}{ }^{\max }(2100-2500 \mathrm{kPa})$, and the difference cannot be attributed to the depth difference. These specimens were located at the presumed temperature range of $140-80{ }^{\circ} \mathrm{C}$ in the zone of non-metamorphosized clay. It is proposed that these specimens acquired their enhanced apparent preconsolidation stress through the regular heating-cooling cycle. Furthermore, there are two specimens with $\sigma_{\mathrm{v}}{ }^{\max }$ clearly lower than that in the previous zone $(1300 \mathrm{kPa}$, as opposed to $2100-2500 \mathrm{kPa}$ ) at presumed temperature range of $160-200{ }^{\circ} \mathrm{C}$ in the metamorphosized clay, at the location of mineralogical gradients, in the range termed by geognostic profile "hard scaly clay", or thermantite III. It is important to note that the values of plasticity index, water content and void ratio, in this batch are all indistinctly different from those for the previous batch. It therefore is proposed that these specimens acquired their apparent preconsolidation stress through the regular heating-cooling cycle, followed by long-term re-smectitization process. Finally, there is a single specimen at $-3.1 \mathrm{~m}$ with a near reference $\sigma_{\mathrm{v}}{ }^{\max }$. The temperature at this location is not much different from the first batch location, and there is no presence of smectite. The visible peculiarity of this specimen are much higher values of it plasticity index, void ratio and water content. It is suggested that this specimen had an additional geological history, which included such surface processes as weathering or erosion.

Using the above data interpretation, we will reconstruct the hypothetical loading history for I4, and based on the last, chemical-evolution step determine function $B$ and its coefficients. The crucial elements of 
ORCIATICO CLAY - 14 - OEDOMETRIC TESTS

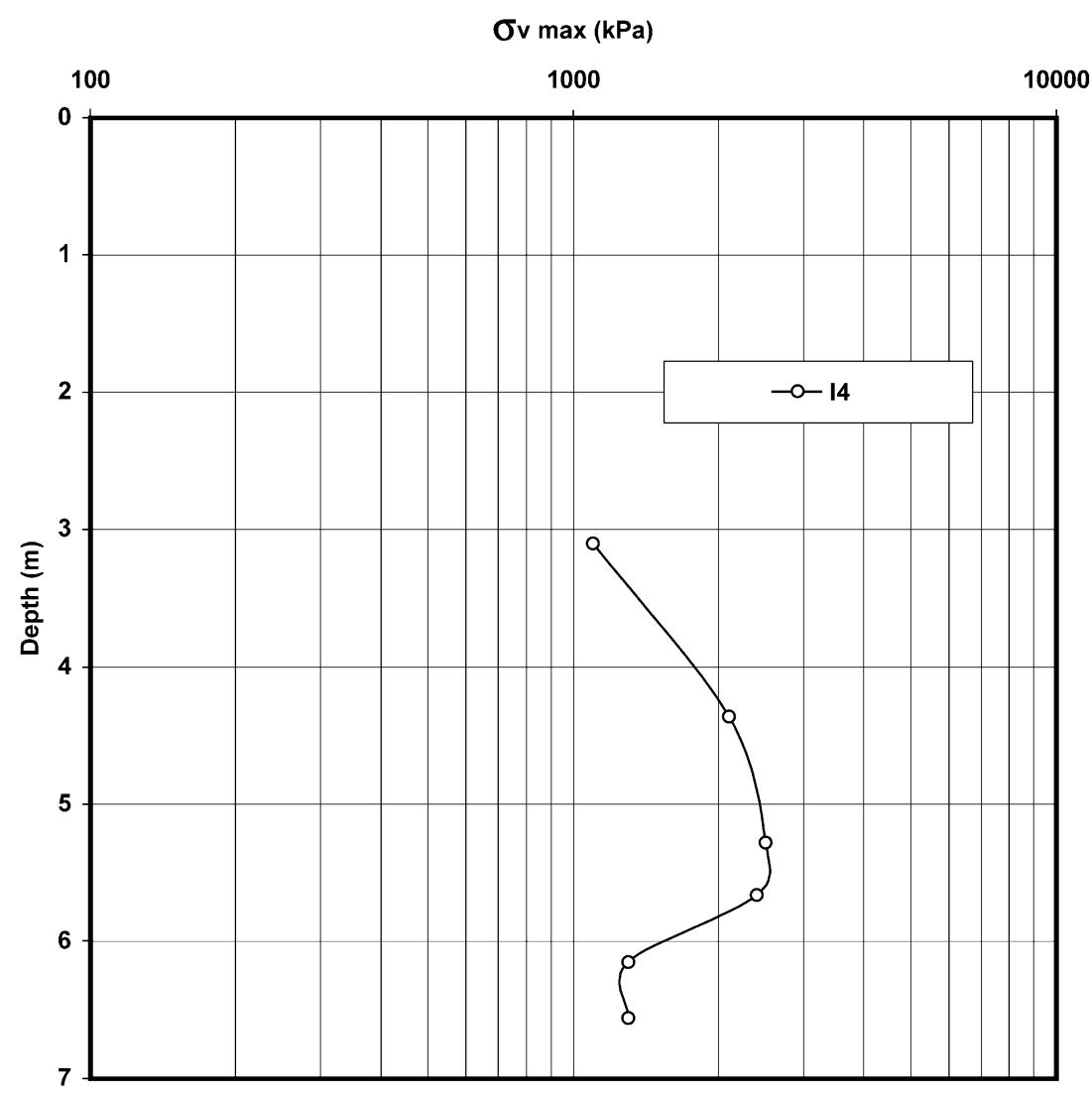

Fig. 9. Distribution of the apparent maximum precompression vertical stress throughout borehole I4.

this history are: $\sigma_{\mathrm{v}}{ }^{\max }$ at the moment of the intrusion, and the in situ effective stress at that moment. While it is quite natural to assume for the latter one the reference $\sigma_{\mathrm{v}}{ }^{\max }$ value determined for the unaltered material, the latter one will be based on a much more arbitrary assumption. In what follows we shall assume as the in situ stress at the moment of intrusion, the lowest value of $\sigma_{\mathrm{v}}{ }^{\max }$ encountered in the whole population of thermally affected specimens, which is $0.45 \mathrm{MPa}$. This is consistent with the understanding in the theory of plasticity of chemical or thermal softening. It is assumed that during such a process $\sigma_{\mathrm{v}}{ }^{\max }$ decreases along with the increase of the variable controlling the softening (temperature). However, the decrease is arrested when value of $\sigma_{\mathrm{v}}{ }^{\max }$ becomes equal to the stress acting on soil. Any further decrease of $\sigma_{\mathrm{v}}{ }^{\max }$ would lead to an unacceptable condition that $f>0$. Thus, for any further increase of temperature or chemical mass transfer, $\sigma_{\mathrm{v}}{ }^{\max }$ must be equal to the in situ stress. This assumption leads to overconsolidation at the moment of intrusion at the level of $\mathrm{OCR}=2.30$.

The history of thermo-chemical loading of the clay element at depth $-6.82 \mathrm{~m}$ in borehole $\mathrm{I} 4$ is shown in Fig. 10. Its first segment, $1-2$, consist in heating from 21 to $34{ }^{\circ} \mathrm{C}$, at no change in smectite content. The latter paleo-temperature corresponds to a reduction of $p_{\mathrm{c} 0}^{\prime}$ from 1.05 to $0.45 \mathrm{MPa}$, which is the hypothesized isotropic stress in situ. Note that for the lack of any information on the evolution of the lateral stress corresponding to $\sigma_{\mathrm{v}}{ }^{\max }$, it is assumed throughout that $p_{\mathrm{c}}^{\prime}=\sigma_{\mathrm{v}}{ }^{\max }$ which is a good approximation for $K_{0}=0.5$ and $M=1$. Heating $(2-3)$ above 34 up to $89.5^{\circ} \mathrm{C}$ 


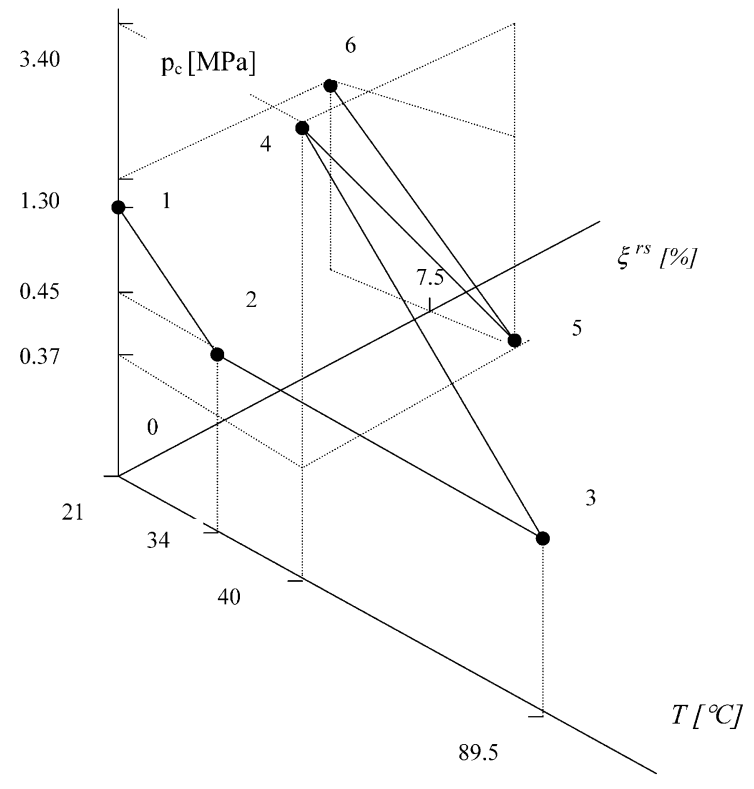

Fig. 10. Hypothetical thermal and chemical history of $p_{\mathrm{co}}{ }^{\prime}$ at borehole $\mathrm{I} 4$, at $-6.81 \mathrm{~m}$.

occurs at a constant stress and with a constant $p_{\mathrm{c}}^{\prime}$. The latter temperature corresponds to the estimated maximum paleo-temperature that occurred at this location. The next step in the material history was cooling (3-4) until $40{ }^{\circ} \mathrm{C}$, still with no change in smectite content. Temperature of $40{ }^{\circ} \mathrm{C}$ is assumed as a rehydration temperature for our illitic complex (taken here as identical to that for dehydrated smectite based on the data of Huang et al., 1994). This cooling brings the value of $p_{\mathrm{c}}^{\prime}$ to $3.40 \mathrm{MPa}$. During the next step (4-5) at constant temperature of $40{ }^{\circ} \mathrm{C}$, re-smectitization takes place, starting at $0 \%$ and terminating at $7.5 \%$ of smectite content by weight of the total soil weight. This step causes the value of $p_{\mathrm{c}}^{\prime}$ to decrease to 0.37 MPa. The final step is further cooling from 40 to 21 ${ }^{\circ} \mathrm{C}$. Note that the value of $p_{\mathrm{c}}^{\prime}=0.37 \mathrm{MPa}$ served to calculate based on purely thermal hardening function $A(\Delta T)$, the formerly used value of $0.37 \mathrm{MPa}$, so that the thermochemical loading trajectory would close on the laboratory obtained $p_{\mathrm{c}}^{\prime}$ of $1.30 \mathrm{MPa}$ equal to the terminal $p^{\prime}$, value. Note also that the value of $p_{\mathrm{c}}^{\prime}=0.37$ MPa is below the estimated in situ stress, and by plasticity principles is not admissible. This may indicate that the estimate of the in situ stress as $0.45 \mathrm{MPa}$ is inaccurate, even though it is based on some analysis of the field data. However, the difference between the two values is less than $3 \%$ of the chemical softening, and may be considered as negligible.

Until point 4 , the material history was purely thermo-mechanical and predictable based on the previously obtained constants. Note that steps $2-3$ was thermoplastic, whereas steps $3-4$ consisted in re-growing of the yield surface during cooling. Therefore, the next steps 4-5 corresponds to the chemical reaction at constant temperature of $40{ }^{\circ} \mathrm{C}$. By our immediately precedent assumption, this entire process is assumed to be entirely elastic. The two terminal points of steps 45 have been obtained from the purely thermal, precedent and subsequent steps. The difference between the values of $p_{\mathrm{c}}^{\prime}$ corresponding to the chemical step of resmectitization from $0 \%$ to $7.5 \%$ of smectite content, has been calculated as $\Delta p_{\mathrm{c}}^{\prime}=3.40-0.37=3.03 \mathrm{MPa}$. The reservation over the accuracy of the attribution of the entire process to elastic phase, as discussed earlier, needs to be reminded.

To obtain the coefficients in function $B\left(\xi^{\mathrm{rs}}\right)$ another data point for $\Delta p_{\mathrm{c}}^{\prime}$, is needed. For that purpose, a history of loading was analogously analyzed for the point located at depth $-7.20 \mathrm{~m}$. At this point, the maximum paleo-temperature has been estimated for $104.5^{\circ} \mathrm{C}$. Thus, cooling until rehydration temperature of $40{ }^{\circ} \mathrm{C}$ amounted to temperature difference of 64.5 ${ }^{\circ} \mathrm{C}$, increasing $\mathrm{pc}$ to the value of 4.71 MPa. Given the fact that the measured "current" $p_{\mathrm{c}}^{\prime}=1.3 \mathrm{MPa}$, after cooling between 40 and $21{ }^{\circ} \mathrm{C}$, is the same as in the other specimen, the chemically induced change of apparent preconsolidation $p_{\mathrm{c}}^{\prime}$, amounts to $4.32 \mathrm{MPa}$. This corresponds to change of smectite content from $0 \%$ to $13 \%$. Combining the two sets of data in a system of two equations with

$\frac{1}{2} \Delta p_{\mathrm{c}}=b_{1} \Delta \xi^{\mathrm{rs}}+b_{2}\left(\Delta \xi^{\mathrm{rs}}\right)^{2}$

one obtains the values of the constants for the chemical softening as

$b_{1}=-24.97 \mathrm{MPa} ; \quad b_{2}=64.24 \mathrm{MPa}$,

The above values allow us to perform basic calculations related to changes in the yield surface size due to re-smectitization. However, it should be reminded that the above thermo-chemo-mechanical calculations were based on two data base points in borehole 
I4/S10, and could not be verified, due to lack of any other points. They were also possible by making a number of simplifying assumptions. From the physical point of view, the assumption that the cooling and chemical reaction phases were sequential and not simultaneous, is the most important one. Clearly, neglecting the whole purely mechanical history of the material, and attributing $p_{\mathrm{c}}^{\prime}=1.3 \mathrm{MPa}$ to the end of the thermo-chemical history was necessary, but not ascertained, due to lack of any data. From the modeling point of view, the most important assumptions consisted in neglecting the effect of coupling between temperature, plastic strain and chemical changes and limiting the chemical effect to one single reaction of re-smectitization. Nevertheless, the calculated coefficients open a possibility to simulate, even if approximately, the long-term effects of chemical history in clays subjected to nuclear waste heat.

\section{Conclusions}

A chemo-thermo-plastic model for illitization and resmectitization of clays developed as an extension of Cam-clay model has been used to quantify the extent of long-term changes in some mechanical properties of clay at Orciatico site of natural analog of nuclear waste disposal. Such goal was achieved, if only in an approximate and strictly focused way. An essential portion of this effort consists in assessing mineralogical changes observed at the site and identifying those that are believed pertinent to changes in mechanical properties of clay.

From the chemo-mechanical point of view the analog at Orciatico has revealed three unusual features: first, the presence of neo-formed smectite, throughout the entire contact and thermantite zone; second, a visibly distinct mechanical properties of the clay in the thermally affected consisting in decrease in deformability, and increase in brittleness; third, the presence of micro-fracturation in large areas of the metamorphic aureole and the adjacent areas. The two first aspects have been considered in the performed analysis, while the last one due to a lack of any quantitative data, was only addressed conceptually. It was concluded that formation of neo-smectite occurred on the basis of the indigenous illite, and to a lesser extent chlorite intergrade and I/S mixed layer. Such change is an inverse one to many previously studied analogs, where illitization of smectite was the dominant reaction. The analog at Skye shows a similar pattern to that at Orciatico. Resmectitization was also judged to be most significant mineralogical change affecting mechanical properties of soil. While the possibility of such outcome of heating of natural clay mixture was welcome news from the hydraulic point of view, for the lower permeability of smectite vis-à-vis illite, it was much less good news from the mechanical point of view. Concomitant dissolution of quartz is believed to had a lesser impact because it produced nearly equally strong feldspar and plagioclase.

As far as modeling is concerned, the following remarks may be offered. Firstly, it is noted that time is not a variable in the presented model, which as a plasticity model, is by definition rate independent. The time effect may be introduced through the simulation of changes in thermal and chemical variables resulting from the reaction rates and/or transport of heat and species. However, scenarios regarding the mechanisms of species and water migration in the post intrusion heating/cooling cycle are currently lacking. Secondly, the focus of the mechanical evolution was on "chemical softening" occurring during mineralogical transformation, resulting in loss of "strength" in terms of the apparent maximum preconsolidation stress due to chemical reaction. It was assumed that this process has occurred after clay has cooled down to $40{ }^{\circ} \mathrm{C}$, as suggested by laboratory tests by Huang et al. (1994). Thus, further assumption was made that the initial thermal process of heating to $105^{\circ} \mathrm{C}$ and cooling to 40 ${ }^{\circ} \mathrm{C}$ was in the absence of any reaction, and in turn that the resmectitization occurred at constant temperature of $40^{\circ}$, followed by final cooling to $20{ }^{\circ} \mathrm{C}$. Thus, it was assumed that the heating, cooling and chemical reaction phases were sequential, and not simultaneous. This effectively allowed us to completely decouple thermal and chemical parts of the process.

The analysis of the thermal, short-term test on previously thermally unaffected specimens from the site provided parameters of thermal softening. Chemical softening parameters were identified by performing back analysis of the thermo-chemical history of the samples from the borehole at the chemically affected site. Data of lower than reference apparent maximum preconsolidation stress were attributed to the chemical variable of smectite content at specific 
sampling points. The portion of the loss in strength attributable to smectitization appears substantial, amounting to about $3.00 \mathrm{MPa}$ in terms of the apparent preconsolidation stress. It must be noted again that the last portion of the chemical softening between 0.45 and $0.37 \mathrm{MPa}$, which constituted less than a $3 \%$ of the total loss of strength was attributed to the elastic process rather than plastic, to allow us the identification process to be confined to elastic range.

Clearly, neglecting the whole portion of the geological history of the material, that might have consisted in stress relief due to overburden reduction, and attributing $p_{\mathrm{c}}^{\prime}=1.3 \mathrm{MPa}$ to the end of the thermochemical history was necessary, but not ascertained, again due to lack of any data. From the modeling point of view, the key simplifying assumptions consisted in neglecting the effect of coupling between temperature, plastic strain and chemical changes and limiting the chemical effect to one single reaction of resmectitization. Nevertheless, the calculated coefficients open a possibility to simulate, even if approximately, the long-term effects of chemical history in clays subjected to nuclear waste heat.

The presented work should be treated rather as a feasibility evaluation for the application of the chemo-thermo-mechanical Cam-clay model for the natural analog study, and not as a technical simulation. It revealed a series of hypotheses that needed to be considered, as well as a series of shortcomings, in terms of missing elements both for chemo-mechanical mod$\mathrm{el}$, such as the hardening formulae for the coupled thermo-chemical processes, as well as in terms of lacking complete scenarios of mineralogical processes, including transport of species in and out to the zone of the analogy. Finally, this work also suggests that the problem in question should be treated as a fully coupled reaction - deformation - transport modeling problem, and our appreciation of it, while quite good in each area separately, still is very incomplete especially in regard to the interfaces between these classes of phenomena.

\section{References}

Atabek, R., Lajaudie, A., Lechelle, J., Pusch, R., 1990. Pilot field experiment with canister embedding clay under simulated repository conditions. Engineering Geology 28 (3-4), 291-302.
Baldi, G., Hueckel, T., Pellegrini, R., 1988. Thermal volume changes of the mineral-water system in low porosity clay soil. Canadian Geotechnical Journal 25 (4), 807-825.

Baldi, G., Hueckel, T., Peano, A., Pellegrini, R., 1990. Developments in modelling of thermo-hydro-geomechanical behaviour of Boom clay and clay based buffer materials, Report FI 1W/ 0150 (A), for European Economical Community, vols. 1 and 2.

Benvegnu, F., Brondi, A., Polizzano, C., 1988. Natural Analogues and evidence of long term isolation capacity of clays occurring in Italy. CEC Report EUR 11896.

Biot, M.A., 1977. Variational-Lagrangian irreversible thermodynamics of initially-stressed solids with thermomolecular diffusion and chemical reactions. Journal of Mechanics and Physics of Solids 25, 289-307.

Campanella, R.G., Mitchell, J.K., 1968. Influence of temperature variations on soil behavior. ASCE Journal of the Soil Mechanics and Foundations Division 94 (SM3), 709-734.

De Olmo, C., Fioravante, V., Gera, F., Hueckel, T., Mayor, J.-C., Pellegrini, R., 1996. Thermo-mechanical properties of deep argillaceous formations. Engineering Geology 41, 87-102.

Ferry, J.M., Mutti, L.J., Zuccala, G.J., 1987. Contact metamorphism/hydrothermal alteration of Tertiary basalts from the Isle of Skye, Northwest Scotland. Contributions to Mineralogy and Petrology 95, 166-181.

Gera, F., Hueckel, T., Peano, A., 1996. Critical issues in modelling of the long-term hydro-thermal performance of natural clay barriers. Engineering Geology 41, 17-33.

Graham, J., Chandler, N.A., Dixon, D.A., Roach, P.J., To, T., Wan, A.W.L., 1996. The buffer/container experiment: volume 4results, synthesis, issues, Review Report, Fuel Waste Technology, AECL, Whiteshell Labs., Pinawa, Manitoba, Canada.

Hetzel, F., Tessier, D., Jaunet, A.-M., Doner, H., 1994. The microstructure of three $\mathrm{Na}^{+}$smectites: the importance of particle geometry on dehydration and rehydration. Clays and Clay Minerals 42 (3), 242-248.

Huang, W.L., Basset, W.A., Wu, T.C., 1994. Dehydration and rehydration of montmorillonite at elevated pressures and temperatures monitored using synchrotron radiation. American Mineralogist $79,683-691$.

Hueckel, T., 1992. Water-mineral interaction in hygro-mechanics of clays exposed to environmental loads: a mixture approach. Canadian Geotechnical Journal 29, 1071-1086.

Hueckel, T., 1997. Chemo-plasticity of clays subjected to flow of a single contaminant and stress. International Journal of Numerical and Analytical Methods in Geomechanics 21 (1), 43-72.

Hueckel, T., 2002. Reactive plasticity for clays during dehydration and rehydration: Part I. Concepts and options. International Journal of Plasticity, in press.

Hueckel, T., Baldi, G., 1990. Thermoplastic behavior of saturated clays: an experimental constitutive study. Journal of Geotechnical Engineering, ASCE 116 (12), 1778-1796.

Hueckel, T., Borsetto, M., 1990. Thermoplasticity of saturated soils and shales: constitutive equations. Journal of Geotechnical Engineering, ASCE 116 (12), 1765-1777.

Hueckel, T., Pellegrini, R., 1996. A note on thermo-mechanical anisotropy of clays. Engineering Geology 41, 171-180.

Hueckel, T., Pellegrini, R., Del Olmo, C., 1998. Constitutive proper- 
ties of thermo-elasto-plastic behavior of deep carbonatic clays. International Journal of Numerical and Analytical Methods in Geomechanics 22 (7), 549-574.

Hueckel, T., Tao, F., Cassiani, G., Pellegrino, A., 1999. Reactive plasticity for geological materials with a double structure evolving during aging. In: Picu, R.C., Krempl, E. (Eds.), Constitutive Laws for Engineering Materials, 4th Int. Conference, RPI Troy, NY, pp. 383-387.

Kamei, G., Arai, T., Yusa, Y., Sasaki, N., Sakuramoto, Y., 1990. Estimation of illitization rate of smectite from the thermal history of Murakami deposit, Japan. Mat. Res. Soc. Symp., vol. 176, pp. 657-663.

Kowalski, W.C., 1974. Differentiation in rock strength in the weathered zone due to softening, swelling and shrinkage. Proc. 2nd Congress of IAEG, São Paolo, 143.

Leoni, L., Polizzano, C., Sartori, F., 1986. Nuclear repositories in clays: the Orciatico metamorphic aureole analogy. Applied Clay Science 1, 385-408.

Low, P.F., 1987. Structural component of the swelling pressure of clay. Langmuir 3, 18-25.

Murray, R.S., Quirk, J.P., 1990. Intrinsic failure and cracking of clay. Soil Science Society of America Journal 54 (4), 1179-1184.

Nadeau, P.H., Wilson, M.J., Hardy, W.J., Tait, J.M., 1985. The conversion of smectite to illite during diagenesis: evidence from some illitic clays, from bentonites and sandstones. Mineralogical Magazine 49, 393-400.

Oelkers, E.H., 1996. Physical and chemical properties of rocks and fluids for chemical mass transport calculations. In: Lichtner, P.C., et al. Reactive Transport in Porous Media. Reviews in Mineralogy, vol. 34. Mineralogical Soc. of Am., Washington, DC, pp. 131-192.

Pellegrini, R., Gera, F., Rochelle, C., Boisson, J.Y., Parneix, J.C., Lombardi, S., 1998. Long-term effects of heating in clay rocks: lessons learnt from the study of thermomechanical natural analogues. Proceedings, Int. Workshop on Key Issues in Waste Isolation Research, Barcelona.
Picard, J.-M., Bazargan, B., Rousset, G., 1993. Essai thermo-hydromanique dans une argile profonde-Essai "Cactus", Final Report by G3S, for ANDRA, France.

Pusch, R., Karnland, O., 1996. Physico/chemical stability of smectite clays. Engineering Geology 41 (1-4), 73-86.

Pusch, R., Madsen, F.T., 1995. Aspect of illitization of Kinnekulle bentonites. Clays and Clay Minerals 43 (3), 261-270.

Pytte, A.M., Reynolds, P.C., 1989. The thermal transformation of smectite to illite. In: Naeser, N.D., McCulloh, T.H.Thermal History of Sedimentary Basins. Springer, New York.

Rizzo, S., 1996. Indagini Geofisiche per la determinazione della geometria della intrusione magmatica di Orciatico. Report of University of Rome, La Sapienza.

Schoen, R., White, D.E., 1966. Hydrothermal clay minerals in granodiorite of the Main Terrace, Steamboat Springs, Nevada. Clays and Clay Minerals 13, 121-122.

Steiner, A., 1968. Clay minerals in hydro-thermally altered rocks at Wairakei, New Zealand. Clays and Clay Minerals 16, 193-213.

Van Genuchten, M.Th., Wierenga, P.J., 1976. Mass transfer studies in sorbing porous media: I. Analytical solutions. Soil Science Society of America 40 (4), 473-480.

Weaver, C.E., 1960. Possible use of clay minerals in the search for oil. Bulletin of American Association of Petroleum Geologists 44, 1505-1518.

Weaver, C.E., Broekstra, B.R., 1984. Illite-mica. In: Weaver, C.E. (Ed.), Shale Slate Metamorphism in Southern Appalachians. Elsevier, Amsterdam.

Weber, K., 1972. Notes on determination of illite crystallinity. Neues Jahrbuch fuer Mineralogie, Abhandlungen 6, 267-276.

Whitney, G., Velde, B., 1993. Changes in particle morphology during illitization: an experimental study. Clays and Clay Minerals 41 (2), 209-218.

Wu, T.C., Basset, W.A., Huang, W.L., Guggenheim, S., Koster van Groos, A.F., 1997. Montmorillonite under high $\mathrm{H}_{2} \mathrm{O}$ pressure: stability of hydrate phases, rehydration hysteresis, and the effect of interlayer cations. American Mineralogist 82, 69-78. 